\title{
Intermediate-Scale Laboratory Experiments of Subsurface Flow and Transport Resulting from Tank Leaks
}

\section{Oostrom \\ TW Wietsma}

September 2014

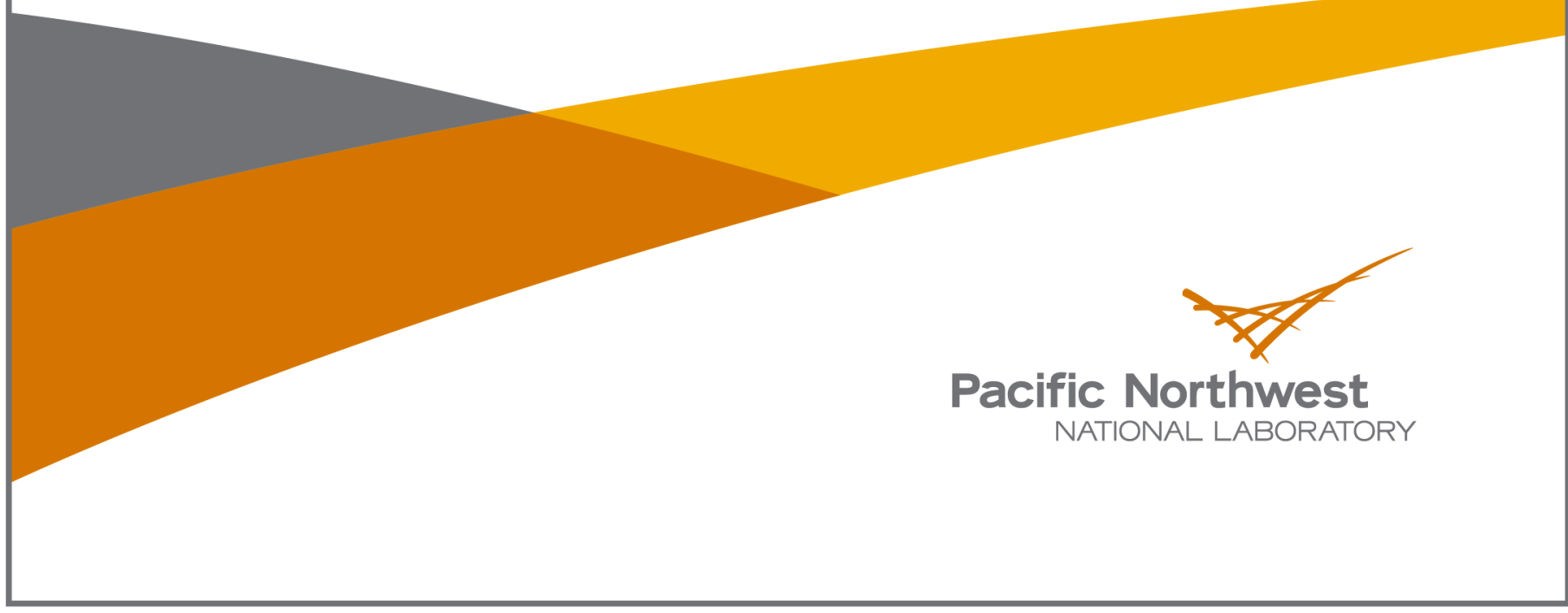




\title{
DISCLAIMER
}

This report was prepared as an account of work sponsored by an agency of the United States Government. Neither the United States Government nor any agency thereof, nor Battelle Memorial Institute, nor any of their employees, makes any warranty, express or implied, or assumes any legal liability or responsibility for the accuracy, completeness, or usefulness of any information, apparatus, product, or process disclosed, or represents that its use would not infringe privately owned rights. Reference herein to any specific commercial product, process, or service by trade name, trademark, manufacturer, or otherwise does not necessarily constitute or imply its endorsement, recommendation, or favoring by the United States Government or any agency thereof, or Battelle Memorial Institute. The views and opinions of authors expressed herein do not necessarily state or reflect those of the United States Government or any agency thereof.

\author{
PACIFIC NORTHWEST NATIONAL LABORATORY \\ operated by \\ BATTELLE \\ for the \\ UNITED STATES DEPARTMENT OF ENERGY \\ under Contract DE-AC05-76RL01830
}

Printed in the United States of America
Available to DOE and DOE contractors from the Office of Scientific and Technical Information,
P.O. Box 62, Oak Ridge, TN 37831-0062;
ph: (865) 576-8401
fax: (865) 576-5728
email: reports@adonis.osti.gov

\author{
Available to the public from the National Technical Information Service, \\ U.S. Department of Commerce, 5285 Port Royal Rd., Springfield, VA 22161 \\ ph: (800) 553-6847 \\ fax: (703) 605-6900 \\ email: orders@ntis.fedworld.gov \\ online ordering: http://www.ntis.gov/ordering.htm
}

This document was printed on recycled paper. 


\section{Intermediate-Scale Laboratory Experiments of Subsurface Flow and Transport Resulting from Tank Leaks}

M Oostrom

TW Wietsma

September 2014

Prepared for

the U.S. Department of Energy

under Contract DE-AC05-76RL01830

Pacific Northwest National Laboratory

Richland, Washington 99352 



\section{Summary}

Washington River Protection Solutions contracted with Pacific Northwest National Laboratory in fiscal year 2011 (FY11) to conduct laboratory experiments and supporting numerical simulations to improve the understanding of water flow and contaminant transport in the subsurface between waste tanks and ancillary facilities at Waste Management Area C. The work scope for FY11 included two separate sets of experiments:

- Small flow cell experiments to investigate the occurrence of potential unstable fingering resulting from leaks and the limitations of the STOMP (Subsurface Transport Over Multiple Phases) simulator to predict flow patterns and solute transport behavior under these conditions. Unstable infiltration may, under certain conditions, create vertically elongated fingers potentially transporting contaminants rapidly through the unsaturated zone to groundwater. The types of leak that may create deeply penetrating fingers include slow release, long duration leaks in relatively permeable porous media. Such leaks may have occurred below waste tanks at the Hanford Site.

- Large flow cell experiments to investigate the behavior of two types of tank leaks in a simple layered system mimicking the Waste Management Area C. The investigated leaks include a relatively large leak with a short duration from a tank and a long duration leak with a relatively small leakage rate from a cascade line.

The main objective of the small flow cell experiments was to test the ability of the numerical simulator STOMP to predict overall plume behavior and arrival times of conservative tracers in two different porous media for a relatively large range in injection rates. The large flow cell experiments were conducted to visualize flow and transport from short duration, fast leak and from long duration, slow leak scenarios.

\section{Small Flow Cell Experiments}

Infiltration experiments were conducted in a small flow cell $(50-\mathrm{cm}-$ long by $40-\mathrm{cm}$-high by 5 -cmwide) packed with sand and gravel. The hydraulic conductivity of the gravel was approximately five times larger than for the sand. Good agreement was observed between the experimental and numerial breakthrough curves for sand. The agreement indicates that for the chosen infiltration rates, in combination with the hydraulic conductivity of the sand, continuum-based models are able to produce a reasonable correpondance with experimental observations in terms of breakthrough behavior, although large differences clearly exist between the observed and modeled plume shapes in the unsaturated zone. For the infiltration experiments in gravel, the agreement between experiments and simulations was not nearly as good because the experimentally observed bromide breakthrough started well before the numerically predicted breakthrough for all experiments. The main reason for the larger decrepancies was

the limited number of fingers that formed in the more conductive gravel, compared to those that formed in the sand, for the same infiltration rate. As a result, the cross-sectional areas in the gravel experiments were smaller, resulting in a more rapid transport of water through the gravel and generally faster plume arrival times in this porous medium. For gravel, the numerical model overpredicted the tracer arrival times for all experiments, even for the $25-\mathrm{mL} / \mathrm{min}$ experiment. Even at this relatively high rate, the hydraulic conductivity of the gravel was apparently not exceeded. 
The results suggest that unstable fingering behavior is strongly related to the combination of hydraulic conductivity and infiltration rate because flow instabilities are more likely for low leakage conditions in highly permeable sediments. Under these conditions, flow and transport are poorly simulated by the continuum-based model. The small flow cell experiments show that, at this scale and for the tested uniform sand and gravel, unstable infiltration may create vertically elongated fingers potentially transporting contaminants rapidly through the unsaturated zone to groundwater. However, it is important to recognize that these experiments are part of an initial study examining conditions resulting in unstable downward migration. The experimental results cannot be directly transferred to the field where the likelihood of unstable flow development would be limited by the occurrence of textural interfaces and the presence of non-uniform sediments containing smaller grains. Both aspects increase the impact of capillary action, reducing the formation of downward moving fluid fingers. For the Hanford Site, it is important to establish a database for the various tanks describing lower- and upper-bound estimates of leak volumes, durations, and rates in combination with sediment hydraulic conductivity. Such a database will help identify whether leak infiltration behavior may be simulated appropriately with a continuumbased simulator or whether a dynamic approach is necessary.

\section{Large Flow Cell Experiments}

Two types of leaks were investigated in the large (162-cm-long by $100-\mathrm{cm}$-high by 5 -cm-wide) flow cell. The long duration, slow leak rate experiments resulted in much wider plumes and longer plume arrival times at the groundwater, compared to the short duration, fast leak rate experiment. For both experiment types, good agreement was obtained between experiments and simulations. The satisfactory match between experimental observation and numerical predictions is attributed to the well-defined boundary and initial conditions, independent determination of the hydraulic properties, the relative simplicity of the experimental system, and the lack of the formation of unstable fingers, as observed in the small flow cell experiments. No fingering was observed because the slow injection rates, in combination with the considerable capillary action in these sediment mixtures, did not allow for any viscous fingers to develop. For these kinds of infiltration experiments in materials of relatively low permeability, the capillary forces tend to dominate the viscous forces. Similar to the short duration, fast rate experiments, the STOMP simulator was able to predict the breakthrough behavior of the bromide well. The predicted and observed maximum concentrations were relatively close, as were the occurrence of the observed and simulated times of these concentrations.

The large flow cell experiments conducted in FY11 and described in this report were intended to be followed by subsequent experiments with increased subsurface heterogeneity, a larger range of leakage

conditions and sediment properties, and the inclusion of radioactive contaminants. The work scope has so far not been defined and executed. 


\section{Acknowledgments}

This work was funded by Washington River Protection Solutions (WRPS) under WRPS MOA Number TOC-MOA-PNNL-0002, Rev.1, in accordance with Pacific Northwest National Laboratory's

Prime Contract Number DE-AC05-76RL01830. The experiments and numerical simulations were completed in fiscal year 2011. 



\section{Abbreviations and Acronyms}

$\begin{array}{ll}{ }^{\circ} \mathrm{C} & \text { degree(s) Celsius } \\ \mathrm{cm} & \text { centimeter(s) } \\ \mathrm{cm}^{3} & \text { cubic centimeter(s) } \\ \mathrm{F} & \text { short duration, fast leak (experiment) } \\ \mathrm{ft} & \text { foot(feet) } \\ \mathrm{g} & \text { gram(s) } \\ \mathrm{Gr} & \text { gravel } \\ \mathrm{in} & \text { inch(es) } \\ \mathrm{kg} & \text { kilogram(s) } \\ \mathrm{k}-\mathrm{S}-\mathrm{P} & \text { relative permeability, fluid saturation, and capillary pressure } \\ \mathrm{L} & \text { liter(s) } \\ \mathrm{m}^{2} & \text { square meter(s) } \\ \mathrm{m}^{3} & \text { cubic meter(s) } \\ \mathrm{min} & \text { minute(s) } \\ \mathrm{mL} & \text { milliliter(s) } \\ \mathrm{mm} & \text { millimeter(s) } \\ \mathrm{Pa} & \text { Pascal(s) } \\ \mathrm{ppm} & \text { parts per million } \\ \mathrm{s} & \text { second(s) } \\ \mathrm{S} & \text { long duration, slow leak (experiment) } \\ \mathrm{Sa} & \text { sand } \\ \mathrm{WRPS} & \text { Washington River Protection Solutions } \\ \mathrm{yr} & \text { year(s) } \\ \end{array}$





\section{Contents}

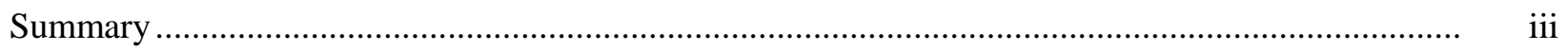

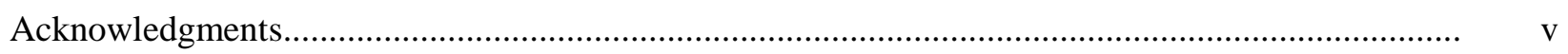

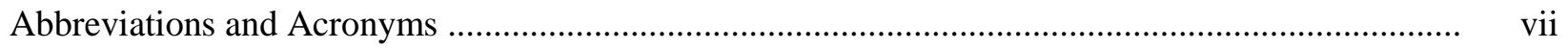

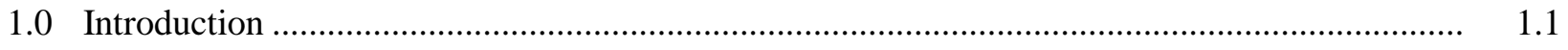

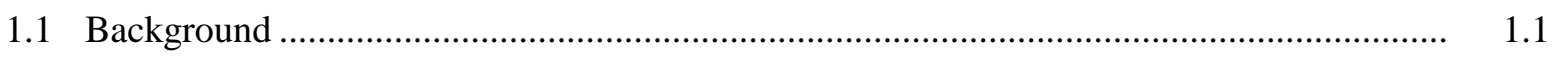

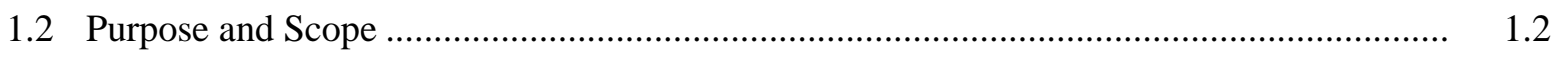

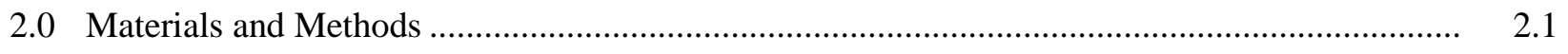

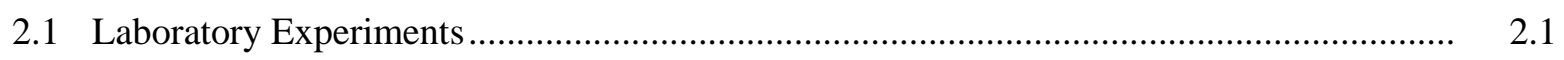

2.1.1 Small Flow Cell Experiments........................................................................ 2.1

2.1.2 Large Flow Cell Experiments....................................................................... 2.2

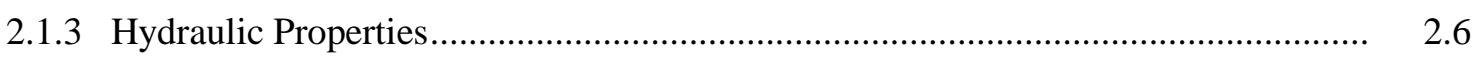

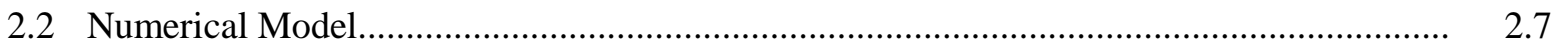

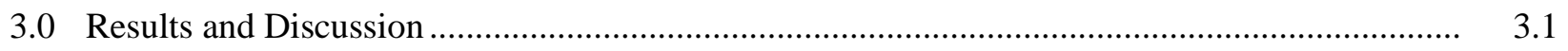

3.1 Small Flow Cell Experiments .............................................................................

3.2 Large Flow Cell Experiments ................................................................................. 3.10

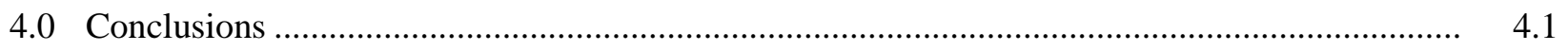

4.1 Small Flow Cell Experiments ........................................................................... 4.1

4.2 Large Flow Cell Experiments ................................................................................. 4.2

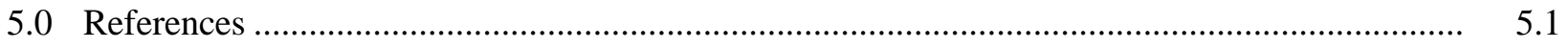

Appendix A - Experimental Plan ............................................................................ A. A 



\section{Figures}

1.1. Subsurface configuration near the C-107, C-108, and C-109 tanks with approximate locations of sediment layers and water table

2.1. Schematic of small flow cell experiments..................................................................... 2.2

2.2. Schematic of large flow cell experiments ........................................................................ 2.4

2.3. Picture of miniature tanks used in the large flow cell experiments........................................... 2.5

2.4. Picture of packed large flow cell before first tank leak experiment....................................... 2.5

2.5. Hydraulic properties experimental apparatus for the determination of hydraulic

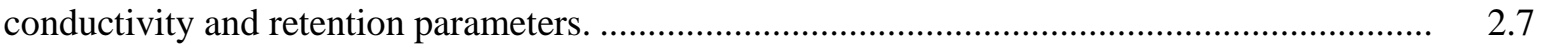

3.1. Plume development after 90 minutes for experiment Sa-1 ............................................... 3.3

3.2. Simulated plume development after 90 minutes for experiment Sa-1 .................................. 3.3

3.3. Plume development after 10 minutes for experiment Sa-25 ............................................. 3.4

3.4. Simulated plume development after 10 minutes for experiment Sa-25 ................................. 3.4

3.5. Plume development after 320 minutes for experiment Sa-1 ................................................. 3.5

3.6. Plume development after 18 minutes for experiment Sa-25 .............................................. 3.5

3.7. Experimental and simulated bromide breakthrough curves for the transport experiments

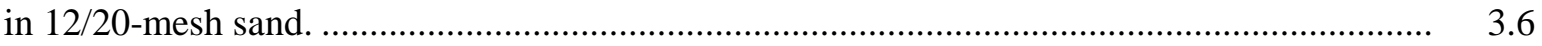

3.8. Plume development after 45 minutes for experiment Gr-1 .............................................. 3.7

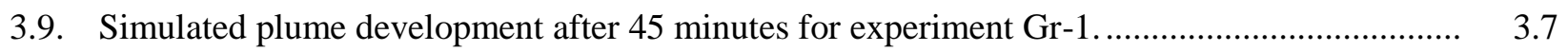

3.10. Plume development after 10 minutes for experiment Gr-1 .............................................. 3.8

3.11. Simulated plume development after 10 minutes for experiment Gr-25 ................................ 3.8

3.12. Plume development after 250 minutes for experiment Gr-1 ............................................. 3.9

3.13. Plume development after 20 minutes for experiment Gr-25 ............................................. 3.9

3.14. Experimental and simulated bromide breakthrough curves for the transport experiments in Hanford Lysimeter Gravel.......................................................................... 3.10

3.15. Dye distribution for Exp. F-1 (a) 1, (b) 4, (c) 8, and (d) 12 hours after start of injection........... 3.12

3.16. Dye distribution for Exp. F-1 (a) 3, (b) 6, (c) 10, and (d) 14 hours after start of injection ......... 3.14

3.17. Measured and simulated normalized bromide concentrations as a function of time for

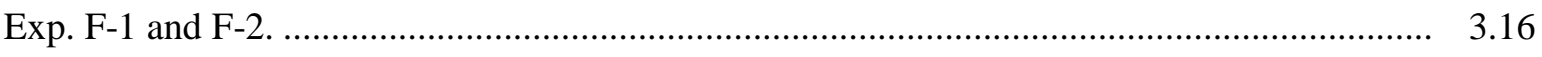

3.18. Dye distribution for Exp. S-1 (a) 0.5, (b) 3, (c) 5, and (d) 7 days after start of injection ........... 3.17

3.19. Dye distribution for Exp. S-2 (a) 1, (b) 3, (c) 5, and (d) 7 days after start of injection .............. 3.19

3.20 Measured and simulated normalized bromide concentrations as a function of time for Exp. S-1 and S-2. 


\section{Tables}

2.1. Overview of injection flow rates and groundwater injection rates for small flow cell experiments in 12/20-mesh sand and Hanford Lysimeter Gravel

2.2. Particle size distribution of composite $\mathrm{H} 1 / \mathrm{H} 3$ gravels and $\mathrm{H} 2$ sand sediments used in the large flow cell experiments.

2.3. Overview of the four experiments conducted in the large flow cell

2.4. Hydraulic properties of 12/20-mesh sand and Hanford Lysimeter Gravel used in the small flow cell experiments.

2.5. Hydraulic properties of composite $\mathrm{H} 1 / \mathrm{H} 3 \mathrm{Gravel}$ and $\mathrm{H} 2$ Sand used in the large flow cell experiments.

3.1. Simulated and experimentally observed arrival times for the experiments conducted in Hanford Lysimeter Gravel and 12/20-mesh sand 


\subsection{Introduction}

It has been suggested that unstable infiltration may, under certain conditions, create vertically elongated unstable displacements of air by water (i.e., fingers) potentially transporting contaminants rapidly through the vadose zone to groundwater. The types of leak that may create these deeply penetrating fingers include slow release, long duration leaks in relatively permeable porous media. Such leaks may have occurred below waste tanks at the Hanford Site. Washington River Protection Solutions (WRPS) contracted with Pacific Northwest National Laboratory in fiscal year 2011 (FY11) to conduct laboratory experiments and supporting numerical simulations to improve the understanding of water flow and contaminant transport in the subsurface between waste tanks and ancillary facilities at Waste Management Area C.

\subsection{Background}

Unstable flow during infiltration in unsaturated porous media has been studied for many years and is known to be associated with a number of existing conditions, including vertical flow from a fine-textured layer to a coarse one (Baker and Hillel 1990), infiltration into water-repellent soil (Hendrickx et al. 1993), and two-phase flow involving two fluids of contrasting density and viscosity (Chuoke et al. 1959). More recently, unstable flow has been demonstrated to occur during infiltration into homogeneous soil at a rate substantially less than the saturated hydraulic conductivity (Geiger and Durnford 2000), and during redistribution following infiltration in homogeneous soil (Wang et al. 2003). Glass et al. (1989) showed in flow cell experiments that wetting-front instability, or gravity-driven fingering, can occur during vertical infiltration. They found that fingers persist over long periods of constant infiltration and in subsequent infiltration cycles.

Unstable flow, such as fingering behavior, is not explicitly included in continuum-based simulators such as the STOMP (Subsurface Transport Over Multiple Phases) model (White and Oostrom 2006). Fürst et al. (2009) demonstrated by means of a mathematical proof that Richards' equation, in principle, cannot describe finger-like solutions for three-dimensional homogeneous unsaturated porous media flow, subject to monotone boundary conditions. They showed that for any reasonable type of homogeneous porous material, the result is not dependent on any particular form of the hydraulic conductivity or the retention curve. The authors discussed an alternative approach to finger flow modeling that uses the ideas of cellular automata. This particular method is typically not included in continuum simulators like STOMP.

Jury et al. (2003) commented that the conventional Richards' flow equation cannot predict the occurrence, transport, or final extent of fingers unless both hysteresis and some representation of waterentry pressure are included. Without these effects, capillary diffusion will smooth out fingers at the moment of formation and allow the water in the matrix between fingers to move downward. They presented a conceptual model that represents the development of unstable flow in uniform soils during redistribution. The flow instability results in the propagation of fingers that drain water from the wetted soil matrix until equilibrium is reached. The model uses soil retention and hydraulic functions, plus relationships describing finger size and spatial frequency. The model assumes that all soils are unstable during redistribution, but shows that only coarse-textured soils will form fingers capable of moving 
appreciable distances. Once a finger forms, it moves downward at a rate governed by the rate of the loss of water of the finger from the soil matrix, which can be predicted from the hydraulic conductivity function. Fingers are assumed to stay narrow as a result of hysteresis, which prevents lateral diffusion. The draining front in the soil matrix between the fingers is assumed to cease downward movement because water pressure drops below the threshold water matric potential. The threshold potential is not present in the conventional Richards' equation of soil water flow, which explains why unstable flow is not predicted by widely used simulation model codes. To date, the conceptual model proposed by Jury et al. (2003) has not been incorporated into a continuum model. An example of a subsurface fingering conceptual model that has been incorporated into a numerical simulator is the theory discussed by Chapwanya and Stockie (2010). The governing equations and corresponding numerical scheme are based on the work of Nieber et al. (2003) in which non-monotonic saturation profiles are obtained by supplementing the Richards' equation with a nonequilibrium capillary pressure-saturation relationship, and including hysteretic effects. Due to its complexity, the Chapwanya and Stockie (2010) model has only been applied to one-dimensional systems.

The research by Fürst et al. (2009), Jury et al. (2003), and Chapwanya and Stockie (2010) clearly indicates that simulation of unstable infiltration is not incorporated in continuum-based models. However, no practical alternatives have been provided that can be used at larger, multi-dimensional scales. Given the lack of available simulators to predict infiltrating fluid fingering, it is important to investigate under which conditions standard continuum-based models, like STOMP, start to produce results that deviate considerably from experimental observation. The infiltration experiments described in this report were therefore designed to demonstrate the limitations of the STOMP model to simulate flow and transport from a series of leaks with different flow rates into two different porous media.

\subsection{Purpose and Scope}

A series of experiments in a small and large flow cell was conducted to demonstrate the infiltration behavior of hypothetical tank leaks in the vadose zone. The small flow cell experiments were conducted to investigate the occurrence of potential unstable fingering resulting from leaks and the limitations of a continuum-based simulator to predict flow patterns and solute transport behavior under these conditions. Large flow cell experiments were conducted to investigate the behavior of two types of tank leaks in a simple layered system mimicking the Waste Management Area C (Figure 1.1). The investigated leaks include a relative large leak with a short duration from a tank and a long duration leak with a relatively small leakage rate from a cascade line.

The ensuing sections describe the experimental materials and methods, results, and conclusions. Appendix A contains the Experimental Plan. 


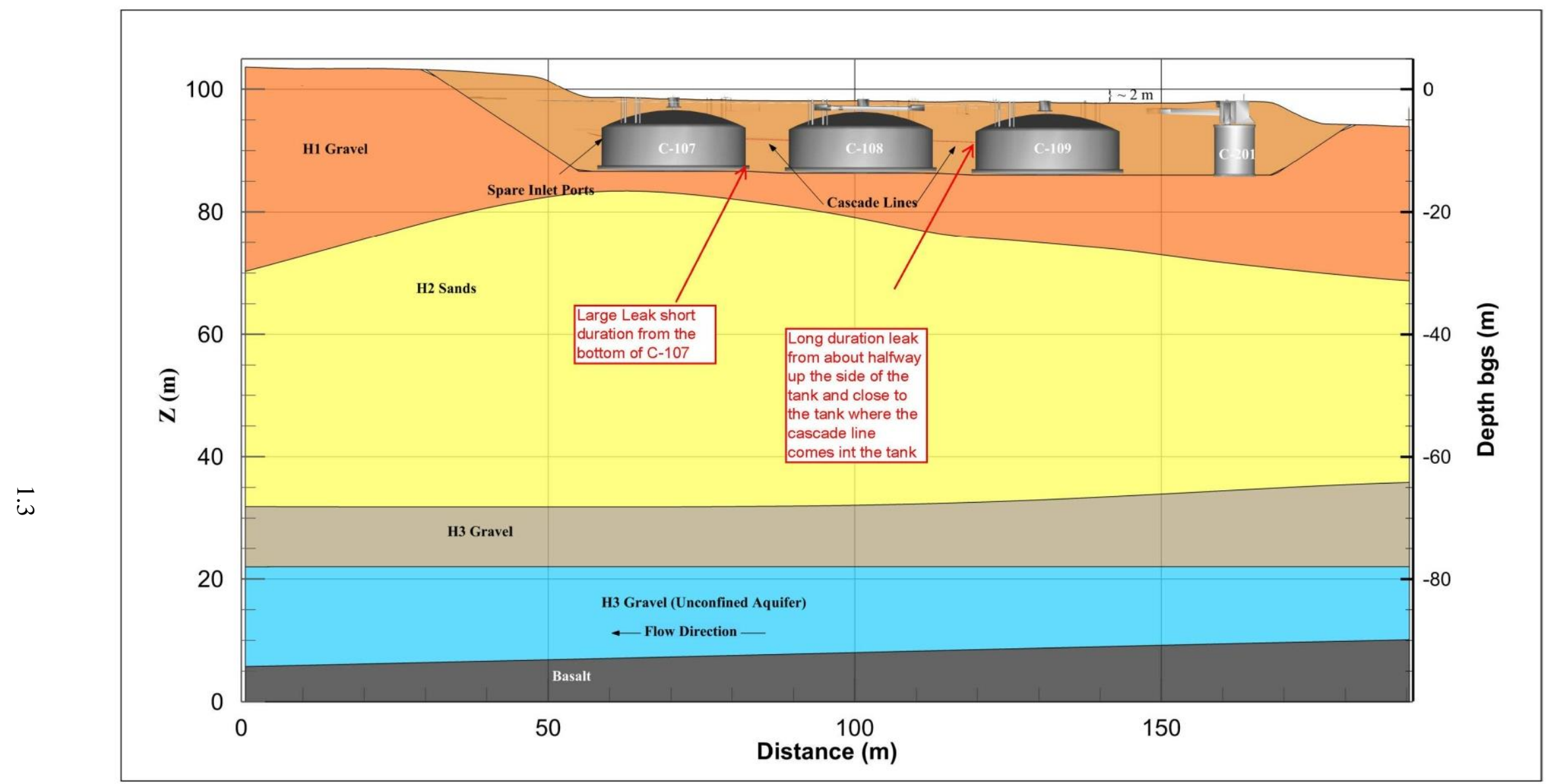

Figure 1.1. Subsurface configuration near the C-107, C-108, and C-109 tanks with approximate locations of sediment layers and water table. The large flow cell was packed to mimic the shown distribution. 



\subsection{Materials and Methods}

The laboratory experiments conducted in a small and large flow cell and the numerical model used to simulate the small flow cell experiments are described below.

\subsection{Laboratory Experiments}

\subsubsection{Small Flow Cell Experiments}

The small flow cell experiments were conducted in a 50-cm-long by 40-cm-high by 5 -cm-wide flow cell consisting of 3/8-in. polycarbonate front and back walls attached to a stainless steel U-shaped frame. A schematic of the flow cell and the experimental design is shown in Figure 2.1. An overview of the five tested injection flow rates and groundwater injection rates $(1,2,5,10$, and $25 \mathrm{~mL} / \mathrm{min})$ for the gravel $(\mathrm{Gr})$ and sand $(\mathrm{Sa})$ experiments conducted is provided in Table 2.1 by experiment number. To contrast infiltration behavior in sand and gravel, a similar series of experiments was conducted in 12/20-mesh sand (Accusand; Unimin Corporation, Le Sueur, MN) and a >2-mm gravel fraction sieved from Hanford lysimeter sediment (Rockhold et al. 1988). The hydraulic properties of the porous media are discussed in Section 2.1.3. Groundwater flow was established by injecting tap water at an inlet located at the left-hand side of the flow cell using rates (Table 2.1) controlled by Allicat Scientific (Tucson, AZ) flow. Denoting the lower left-hand side as $(x=0 \mathrm{~cm} ; z=0 \mathrm{~cm})$, water was allowed to exit the flow cell at $(0 \mathrm{~cm} ; 2 \mathrm{~cm})$ using an outlet at the right-hand side of the flow cell. Tap water containing $100 \mathrm{ppm}$ bromide and 100 ppm Brilliant Blue dye (Sigma-Aldrich Inc.) was injected from the top of the flow cell at $(20 \mathrm{~cm} ; 40 \mathrm{~cm})$ using four separate pumps injecting the water through 1/16-in. stainless steel tubes into the porous medium. In the experiments, the injection flow rate and the groundwater flow rate always were the same to ensure that the dimensionless final bromide concentrations are $\mathrm{C} / \mathrm{C}_{\mathrm{o}}=0.5$. The bromide was analyzed using an ion chromatograph (Dionex Corporation, Sunnyvale, CA).

The Hanford Lysimeter Gravel and the 12/20-mesh sand were premixed in individual batches with $3.5 \mathrm{~g}$ and $10.3 \mathrm{~g}$ tap water per $1000 \mathrm{~g}$ of porous media, respectively, to obtain the irreducible water saturations listed in Table 2.4 (in Section 2.1.3). The flow cell was carefully packed with the moist porous media in 1-cm layers. After each addition, the sediment layers were first gently compacted then the surface was loosened using a 0.3 -cm-diameter rod. Surface loosening minimized the formation of distinct interfaces between the layers. Scoping tests conducted in vertical columns indicated that water redistribution due to movement in both the gravel and the sand was minimal over a 4-week period. Over this time frame, water contents observed using a dual-energy gamma scanner (Oostrom et al. 2005) changed less than $2 \%$ for both porous media. 


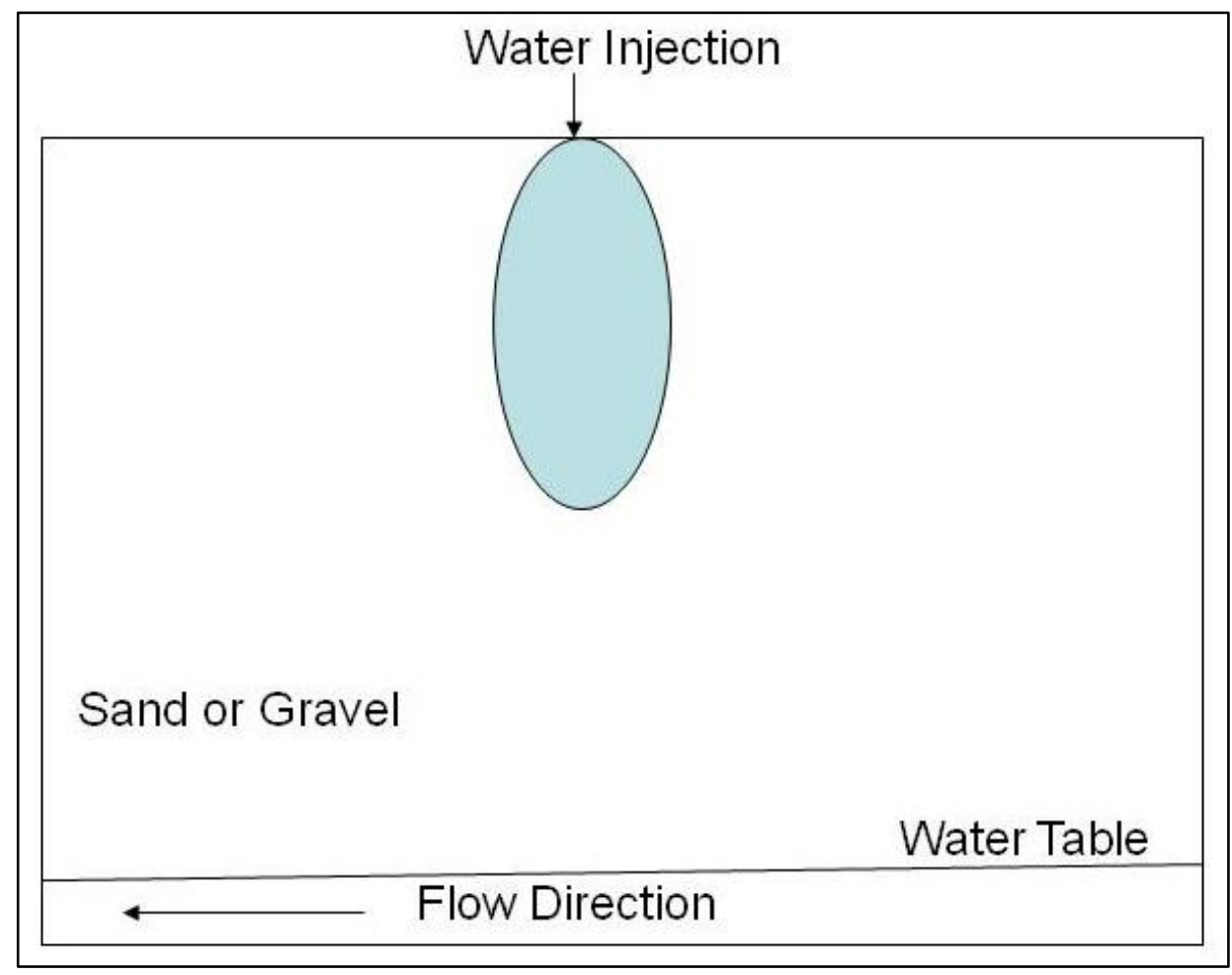

Figure 2.1. Schematic of small flow cell experiments. Tap water containing bromide and dye were injected from the top at the same rate as water was injected horizontally to maintain water table location.

Table 2.1. Overview of injection flow rates and groundwater injection rates for small flow cell experiments in 12/20-mesh sand and Hanford Lysimeter Gravel.

\begin{tabular}{cccc}
\hline $\begin{array}{c}\text { Hanford Lysimeter Gravel } \\
\text { Experiments }\end{array}$ & $\begin{array}{c}\text { 12/20-mesh Sand } \\
\text { Experiments }\end{array}$ & $\begin{array}{c}\text { Injection Flow Rate } \\
(\mathrm{mL} / \mathrm{min})\end{array}$ & $\begin{array}{c}\text { Groundwater Injection } \\
\text { Rate (mL/min) }\end{array}$ \\
\hline Exp. Gr-1 & Exp. Sa-1 & 1 & 1 \\
Exp. Gr-2 & Exp. Sa-2 & 2 & 2 \\
Exp. Gr-5 & Exp. Sa-5 & 5 & 5 \\
Exp. Gr-10 & Exp. Sa-10 & 10 & 10 \\
Exp. Gr-25 & Exp. Sa-25 & 25 & 25 \\
\hline
\end{tabular}

\subsubsection{Large Flow Cell Experiments}

The large flow cell infiltration experiments were conducted in a $162-\mathrm{cm}$-long by 100 -cm-high by 5 cm-wide flow cell consisting of 3/8-in. polycarbonate walls and a stainless steel U-shaped frame and lid. The main requirement of the porous medium configuration to be used in the experiments was that it represent the subsurface below the C-107, C-108, and C-109 tanks shown in Figure 1.1. Characterization data from Brown et al. (2008) were used to determine representative particle size distributions of the sediments. These representative distributions were subsequently reconstructed using available Hanford sediment fractions at the Environmental Molecular Sciences Laboratory. Based on the WRPS's recommendation, the particle size distribution of the $\mathrm{H} 1$ and $\mathrm{H} 3$ Gravels were the same. The particle size distributions used for the reconstructed sediments are listed in Table 2.2. 
Table 2.2. Particle size distribution (\%) of composite $\mathrm{H} 1 / \mathrm{H} 3$ gravels and $\mathrm{H} 2$ sand sediments used in the large flow cell experiments (after Brown et al. 2008).

\begin{tabular}{lcc}
\hline \multicolumn{1}{c}{ Particle Size } & H1 and H3 Gravel & H2 Sand \\
\hline$>2 \mathrm{~mm}$ & 22.1 & 3.2 \\
$1 \mathrm{~mm}-2 \mathrm{~mm}$ & 34.0 & 17.1 \\
$0.5 \mathrm{~mm}-1 \mathrm{~mm}$ & 23.5 & 39.2 \\
$0.25 \mathrm{~mm}-0.5 \mathrm{~mm}$ & 7.5 & 21.5 \\
$0.105 \mathrm{~mm}-0.250 \mathrm{~mm}$ & 5.5 & 8.0 \\
$53 \mu \mathrm{m}-0.105 \mathrm{~mm}$ & 1.8 & 3.5 \\
$<53 \mu \mathrm{m}$ & 5.6 & 7.5 \\
\hline
\end{tabular}

Two types of injection experiments were conducted. The first type represents a large leak with a short duration from the bottom of Tank $\mathrm{T} 1$, while the second type represents a long duration leak, with a relatively small leakage rate, from a cascade line to the left of Tank T3. The two short duration, fast leak experiments are denoted as Exp. F-1 and F-2; the two long duration, slow leak experiments are denoted as Exp. S-1 and S-2. A schematic of the flow cell for these two types of leaks is shown in Figure 2.2. The injected solutions contained 100 ppm bromide and 100 ppm Allura Red AC dye (Sigma-Aldrich Inc.). An overview of the leak injection rates and durations, and the injection rate used to maintain the water table elevation is shown in Table 2.3. The total leak volume for the short duration, fast leak experiments in the flow cell was chosen somewhat arbitrarily based on a few simple geometry considerations. First, a leakage length was computed by assuming that the total T-106 leak volume of $\sim 435 \mathrm{~m}^{3}$ was distributed evenly over the tank bottom surface $\left(\sim 411 \mathrm{~m}^{2}\right)$. It is well known that the large leak was localized but this assumption allows for a conservative conversion of the actual spill size to something that can be used in a two-dimensional flow cell. Next, this leakage length was divided by the ratio of the distance from the tank bottom in the field to that distance in the flow cell $(\sim 100)$. Finally, that number was multiplied by the flow cell tank bottom area $\left(\sim 85 \mathrm{~cm}^{2}\right)$ to arrive at a spill volume of $90 \mathrm{~cm}^{3}$. The spill duration was arbitrarily set at 4 and 8 hours for Exp. F-1 and F-2, respectively, to allow the four experiments to be completed in FY11. The groundwater injection rate was set at $2 \mathrm{~mL} / \mathrm{min}$ to obtain an approximate Darcy velocity of $0.3 \mathrm{~m} /$ day, which is considered a reasonable number for groundwater conditions at the Hanford Site (Carroll et al. 2011). The much slower rate of 5.45 x 10-3 m/day suggested in a recent report by the U.S. Department of Energy, Richland Operations Office (DOE/RL 2011) was not considered to be practical for the flow cell experiments because bromide in the groundwater would have been transported with a linear velocity of about $1 \mathrm{~cm} /$ day, resulting in experiment durations that would be too long.

The H1/H3 Gravel and the $\mathrm{H} 2$ Sand were premixed in individual batches with $40.8 \mathrm{~g}$ and $46.5 \mathrm{~g}$ tap water per $1000 \mathrm{~g}$ of porous media, respectively, to obtain initial saturations $(0.23$ for $\mathrm{H} 1 / \mathrm{H} 3 \mathrm{Gravel}$ and 0.25 for $\mathrm{H} 2$ Sand) consistent with a recharge rate of $4 \mathrm{~mm} /$ year (DOE/RL 2011) and the retention parameter values listed in Section 2.1.3. The large flow cell was carefully packed with the moist porous media in 1-cm layers. Similar to the procedure for packing the small flow cell, after each addition of approximately $1 \mathrm{~cm}$, the sediments were first gently compacted, then the surface was loosened. Scoping tests conducted in vertical columns indicated that water redistribution due to movement in both the H1/H3 Gravel and the $\mathrm{H} 2$ Sand, when packed to the initial saturations consistent with a recharge of $4 \mathrm{~mm} / \mathrm{yr}$, was small over a 8-week period. Using a dual-energy gamma scanner (Oostrom et al. 2005), the observed water contents over this time frame changed less than $3 \%$ for both porous media. A picture of the 
miniature tanks included in the flow cell, with a radius of $8.5 \mathrm{~cm}$, is shown in Figure 2.3. The flow cell with the packed sediments just before the first experiment is shown in Figure 2.4.

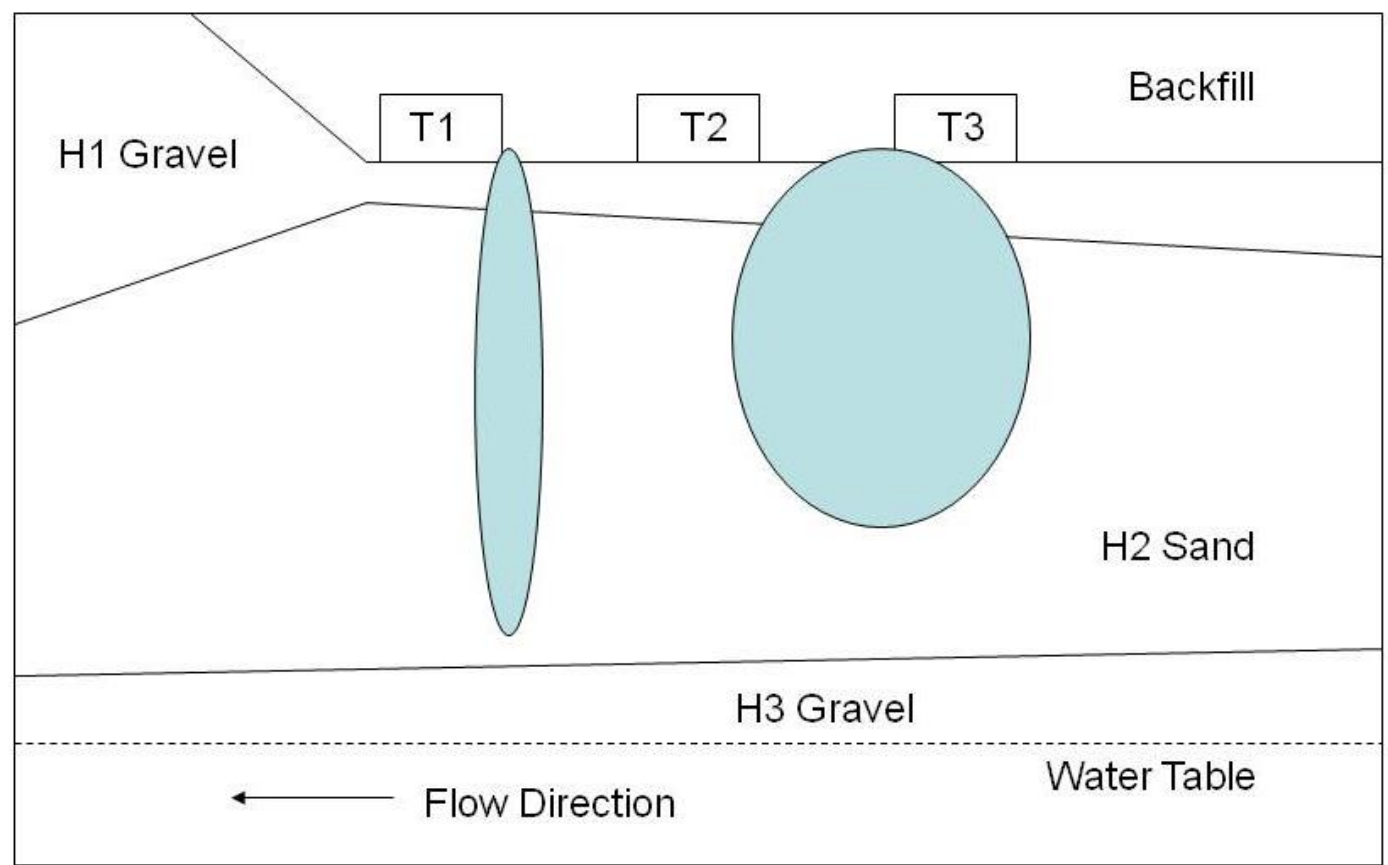

Figure 2.2. Schematic of large flow cell experiments. Tap water containing bromide and red dye were injected from the top to the right of the Tank T1for the short duration, fast leak and to the left of the Tank T3 for the long duration, slow leak experiments. Water was injected horizontally at the right-hand side of the flow cell to maintain water table location.

Table 2.3. Overview of the four experiments conducted in the large flow cell.

\begin{tabular}{cccc}
\hline Experiment Name & $\begin{array}{c}\text { Tank Leak Rate } \\
(\mathrm{mL} / \mathrm{min})\end{array}$ & Tank Leak Duration & $\begin{array}{c}\text { Groundwater Injection } \\
\text { Rate }(\mathrm{mL} / \mathrm{min})\end{array}$ \\
\hline Exp. F-1 & 1 & 90 minutes & 2 \\
Exp. F-2 & 0.5 & 180 minutes & 2 \\
Exp. S-1 & 0.04 & 30 days & 2 \\
Exp. S-2 & 0.02 & 30 days & 2 \\
\hline
\end{tabular}

The two short duration, fast leak experiments are denoted as F-1 and F-2. The two long duration, slow leak experiments are denoted as S-1 and S-2. 


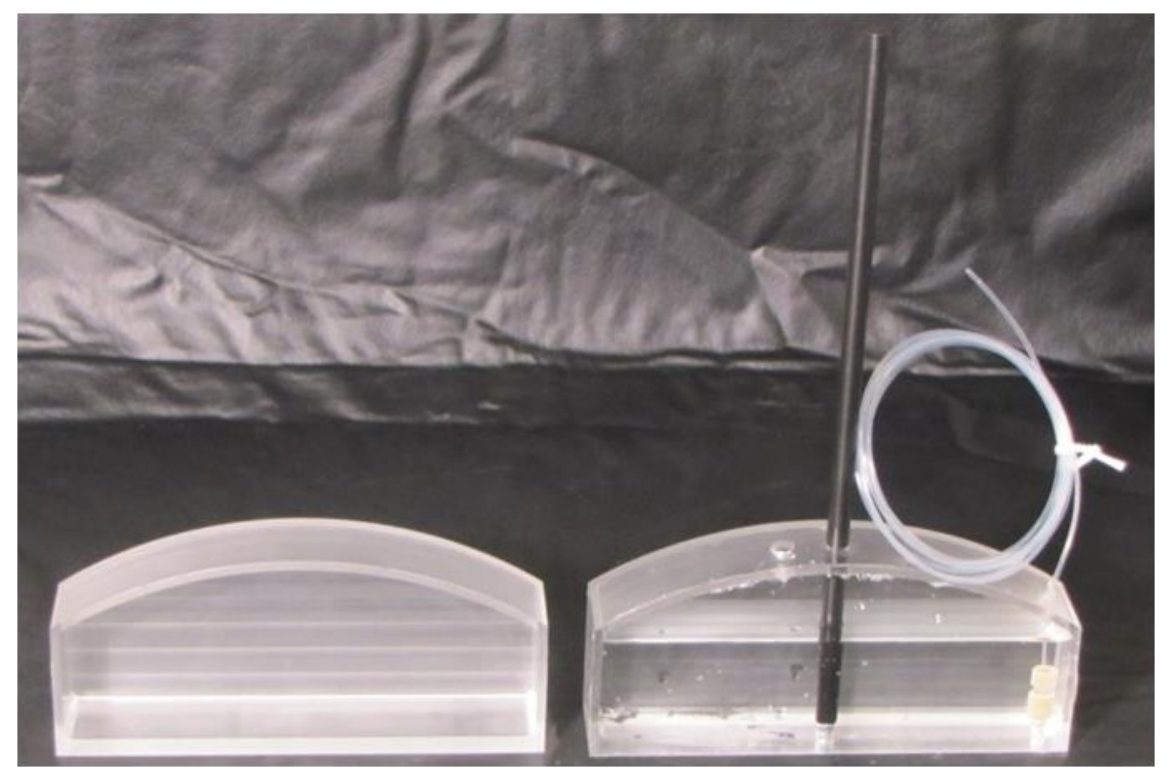

Figure 2.3. Picture of miniature tanks used in the large flow cell experiments. The large rod in the middle could be removed to simulate a fast spill. The tubing/fitting combination at the bottom may be used to simulate a slow spill.

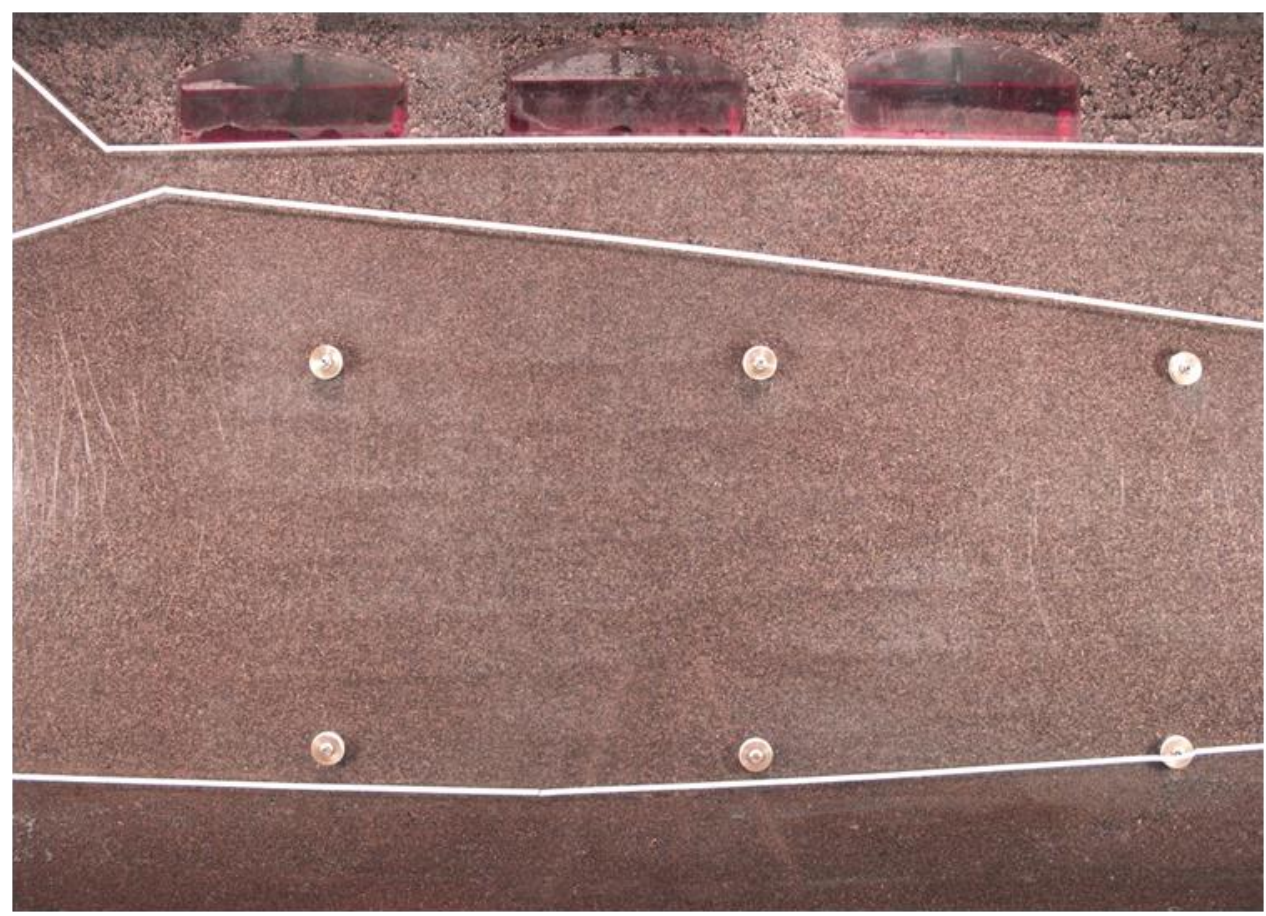

Figure 2.4. Picture of packed large flow cell before first tank leak experiment. 


\subsubsection{Hydraulic Properties}

The hydraulic properties of the sands and gravels used in the small and large flow cell experiments were obtained using procedures described by Schroth et al. (1996) and Wietsma et al. (2009). The hydraulic properties experimental setup is shown in Figure 2.5. The obtained values for the small and large flow cell experiments are listed in Table 2.4 and Table 2.5, respectively. For each material, hydraulic conductivity values were obtained first using the constant head method (Wietsma et al. 2009) for cores $15 \mathrm{~cm}$ long and having an internal diameter of $9.5 \mathrm{~cm}$. The cores were packed in lifts of $1 \mathrm{~cm}$, using the same techniques used for the actual flow cell packing. The porosities listed in Table 2.4 and Table 2.5 were obtained using a particle density of $2.70 \mathrm{~g} / \mathrm{cm}^{3}$ for the Hanford sediments and $2.65 \mathrm{~g} / \mathrm{cm}^{3}$ for the Accusand (Schroth et al. 1996). After packing, the samples were slowly saturated until a saturated equilibrium condition was obtained as indicated by pressure readings from two transducers, located at 2.5 and $12.5 \mathrm{~cm}$ from the bottom of the cores. Hydraulic conductivity values were obtained in triplicate using heads of 7.5 and $15 \mathrm{~cm}$. The average values are listed in Table 2.4 and Table 2.5.

After completing the permeability measurements, a sintered metal plate with an entry pressure of $200 \mathrm{~cm}$ was attached to the bottom of the core and the core was subsequently drained by applying increased air pressure at the top. Water pressures and displaced water were recorded as a function of time. The data were then fitted to the van Genuchten (1980) retention relation using a procedure described by Schroth et al. (1996). The van Genuchten (1980) relation is given by

$$
\theta=\theta_{r}+\left(\theta_{s}-\theta_{r}\right)\left(\frac{1}{1+(\alpha h)^{n}}\right)^{m}
$$

where

$$
\begin{aligned}
\theta & =\text { actual moisture content } \\
\theta_{s} & =\text { saturated moisture content } \\
\theta_{r} & =\text { irreducible moisture content (water volume divided by the total volume } \\
\mathrm{H} & =\text { water pressure head }(\mathrm{cm}), \\
\alpha \text { and } \mathrm{n} & =\text { pore-shape factors, and } \mathrm{m}=1-1 / \mathrm{n} .
\end{aligned}
$$




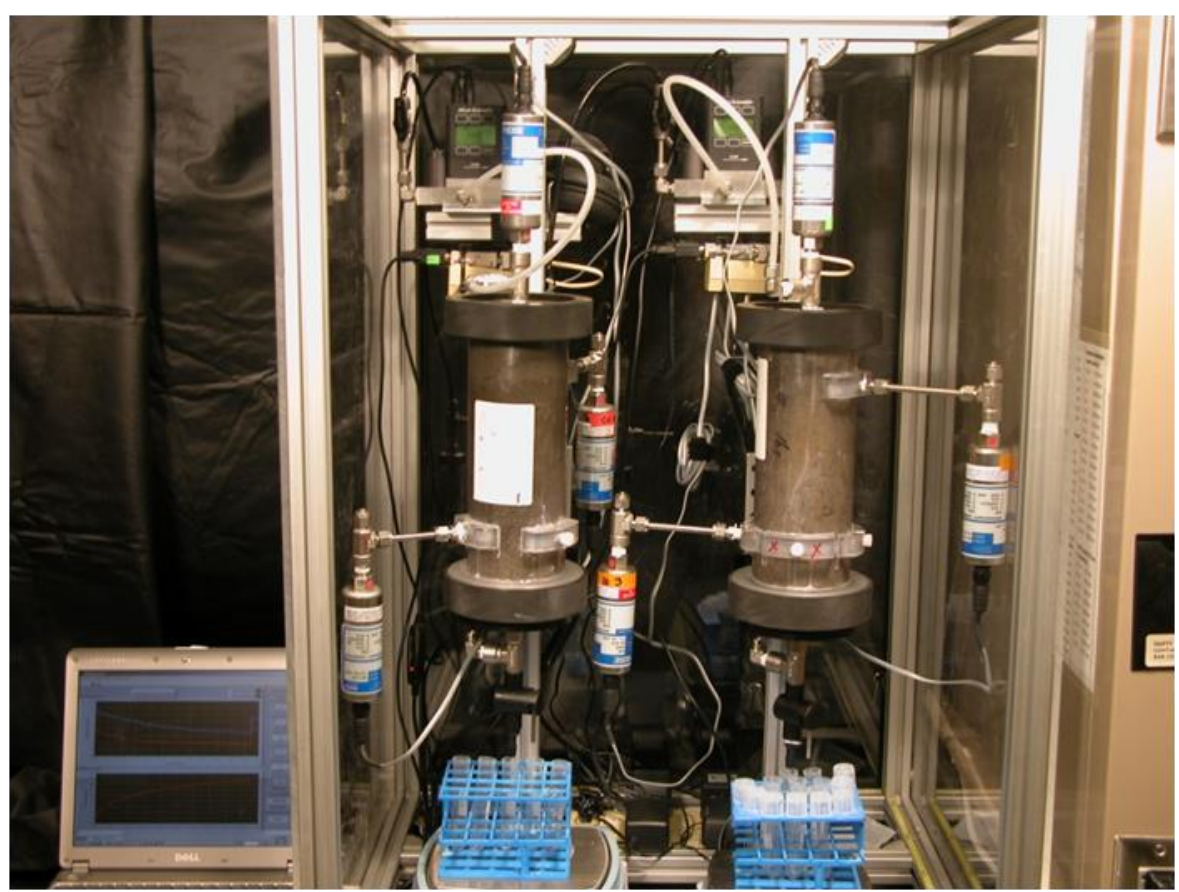

Figure 2.5. Hydraulic properties experimental apparatus for the determination of hydraulic conductivity and retention parameters.

Table 2.4. Hydraulic properties of 12/20-mesh sand and Hanford Lysimeter Gravel used in the small flow cell experiments.

\begin{tabular}{lcc}
\hline \multicolumn{1}{c}{ Property } & 12/20-Mesh Sand & Hanford Lysimeter Gravel \\
\hline Hydraulic Conductivity $(\mathrm{cm} / \mathrm{s})$ & 0.48 & 2.22 \\
van Genuchten $\alpha(1 / \mathrm{cm})$ & 0.18 & 0.59 \\
van Genuchten $n$ & 5.38 & 4.77 \\
Porosity & 0.34 & 0.31 \\
Irreducible Saturation & 0.05 & 0.02 \\
\hline
\end{tabular}

Table 2.5. Hydraulic properties of composite H1/H3 Gravel and H2 Sand used in the large flow cell experiments.

\begin{tabular}{lcc}
\hline \multicolumn{1}{c}{ Property } & H1 and H3 Gravel & H2 Sand \\
\hline Hydraulic Conductivity $(\mathrm{cm} / \mathrm{s})$ & $5.3410^{-2}$ & $2.9710^{-2}$ \\
van Genuchten $\alpha(1 / \mathrm{cm})$ & 0.18 & 0.14 \\
van Genuchten $n$ & 3.22 & 3.03 \\
Porosity & 0.32 & 0.33 \\
Irreducible Saturation & 0.18 & 0.21 \\
\hline
\end{tabular}

\subsection{Numerical Model}

The simulations are conducted using the water mode of the STOMP simulator (White and Oostrom 2006). The fully implicit integrated finite difference mode of the simulator has been used to simulate a variety of unsaturated water flow and solute transport systems related to tank leaks (e.g., White et al. 
2001; Zhang et al. 2004). The applicable governing flow equation is the component mass-conservation equation for water, while solute transport is solved with the solute conservation equation. The governing partial differential equations are discretized following the integrated-volume finite difference method by integrating over a control volume. Using Euler backward time differencing, yielding a fully implicit scheme, a series of nonlinear algebraic expressions is derived. The algebraic forms of the nonlinear governing equations are solved with a multi-variable, residual-based Newton-Raphson iterative technique, where the Jacobian coefficient matrix is composed of the partial derivatives of the governing equations with respect to the primary variables. The algebraic expressions are evaluated using upwind interfacial averaging to fluid density, mass fractions, and relative permeability. Specified weights (i.e., arithmetic, harmonic, geometric, upwind) are applied to the remaining terms of the flux equations. For the simulations described in this report, harmonic averages were used and the maximum number of NewtonRaphson iterations was eight, with a convergence factor of $10^{-6}$.

Secondary variables, those parameters not directly computed from the solution of the governing equations, are computed from the primary variable set through the constitutive relations. In this section, only the relations between relative permeability, fluid saturation, and capillary pressure $(k-S-P)$ pertinent to the conducted simulations are described. The $k-S$ - $P$ relations consist of the van Genuchten (1980) $S$ - $P$ relations in combination with the $k-S$ relations derived from the Mualem (1976) model. The $k-S-P$ relations distinguish between actual and effective saturations. Actual saturations are defined as the ratio of fluid volume to diffusive pore volume. Effective saturations represent normalized actual saturations based on the pore volumes above the irreducible or minimum saturation of the wetting fluid (i.e., aqueous phase liquid).

The computational domains for both the small and large flow cell experiments were discretized into uniform grid cells $1 \mathrm{~cm}$ in the horizontal $x$-direction, $5 \mathrm{~cm}$ in the horizontal $y$-direction, and $1 \mathrm{~cm}$ in the vertical $z$-direction for a total of 2,000 and 16,200 cells for the small and large flow cell experiment simulations, respectively. Similar to the procedures used by White et al. (2001), Freedman et al. (2002), and Zhang et al. (2004), the transient flow and transport simulations were initiated by applying a steady flow solution to the boundary value problem using the initial boundary values. The steady flow initial conditions were generated with a simulation of steady flow conditions. The steady-state flow conditions used were the same as the initial conditions used for the water infiltration simulations containing nonsorbing bromide. The longitudinal dispersivity was chosen to be $0.5 \mathrm{~cm}$ to honor Peclet Number restrictions, which were most likely to occur in the saturated zone where the horizontal pore-water velocity was approximately $1 \mathrm{~m} /$ day. The imposed vertical dispersivity was $0.05 \mathrm{~cm}$. Time-stepping during the transport simulations was controlled by a Courant Number limiting feature, which keeps that number below one. 


\subsection{Results and Discussion}

The results of the injection experiments conducted in the small and large flow cell are described in the sections below. Figures and tables cited in the narrative are presented in the order of their in-text callouts at the end of the section in which they are initially cited.

\subsection{Small Flow Cell Experiments}

The infiltrations at all tested rates $(1,2,5,10$, and $25 \mathrm{~mL} / \mathrm{min})$ resulted in unstable displacements of air by water in the form of fingers in both the sand and the gravel. For both porous medium types, the number of fingers increased with infiltration rate although the unstable behavior was more prominent in the gravel. To illustrate the infiltration process in both porous media, pictures and numerical simulation plots are included in this section. For the sand infiltrations, the results are shown in Figure 3.1 through Figure 3.7. The results for the gravel infiltrations are shown in Figure 3.8 through Figure 3.14.

The plume development after 90 minutes of injection for the slowest infiltration rate $(1 \mathrm{~mL} / \mathrm{min})$ in sand is shown in Figure 3.1. For this case, two major fingers with an approximate width of $1.5 \mathrm{~cm}$ developed and bifurcated several times while traveling from the top of the flow cell to the capillary fringe, which is approximately $5 \mathrm{~cm}$ thick for the 12/20-mesh sand. The simulated plume after the same infiltration time (Figure 3.2) shows a typical vadose zone plume emanating from a source where water is injected at a constant flow rate. The STOMP simulator (White and Oostrom 2006), like any other continuum-based simulator, does not typically produce fingers unless they are triggered by imposing spatially variable porous medium or infiltration rate permutations (Furst et al. 2009). The experimentally observed fingers arrive at the capillary fringe, and subsequently at the water table and flow cell outlet, before the arrival of the simulated plume. This behavior is consistent with the findings of Jury et al. (2003), who stated that contaminants dissolved in the aqueous phase travel faster through the vadose zone in the form of unstable fingers, compared to stable displacement transport from sources with similar source strengths.

In the experiments reported here, as the infiltration rate increased, the number of fingers also increased, as can be seen when comparing Figure $3.3(25 \mathrm{~mL} / \mathrm{min})$ with Figure $3.1(1 \mathrm{~mL} / \mathrm{min})$. For the $25-\mathrm{mL} / \mathrm{min}$ case, the dye reaches the water table in 10 minutes, which is about nine times faster than the 1 $\mathrm{mL} / \mathrm{min}$ case. Because of the increase in the number of unstable fingers, the resulting plume is considerably wider than it is in the $1-\mathrm{mL} / \mathrm{min}$ case (Figure 3.1). As a result of the combination of the increased overall rate and the increased cross-sectional area of the plume in the horizontal direction, the plume arrival time at the capillary fringe increases, but not by a factor 25 . The simulated plume (Figure 3.4) shows a better match with the experimental observations than it does for the experiment at the slower rate. The phenomenon of multiple unstable fingers giving the appearance of a stable, continuum-based displacement (Figure 3.3) has been clearly demonstrated by Zhang et al. (2011) for multiphase systems. Over time, the plumes in the unsaturated zone continue to grow horizontally because of capillarity. Pictures of the plumes when the dye started to exit the flow cell are shown in Figure 3.5 and Figure 3.6 for the $1-\mathrm{mL} / \mathrm{min}$ and $25-\mathrm{mL} / \mathrm{min}$ experiments. 
Experimental and simulated bromide breakthrough curves for the transport experiments in the 12/20mesh sand are shown in Figure 3.7. The mean arrival times $\left(C / C_{0}=0.25\right)$ derived from the plots are listed in Table 3.1. The breakthrough curves indicate an increased apparent mixing with a decreasing infiltration rate. For the higher rates, the concentration increases until the maximum possible concentration $\left(\mathrm{C} / \mathrm{C}_{\mathrm{o}}=0.5\right)$ is reached within minutes. For the experiments with the slower flow rates (1 and $2 \mathrm{~mL} / \mathrm{min}$ ), the plume spreading in the unsaturated zone caused a much slower increase in the measured effluent concentrations. Figure 3.7 also shows that the experimental and predicted breakthrough curves are in general agreement. The general shapes are similar for all infiltration rates and for the 5-, 10-, and $25-\mathrm{mL} / \mathrm{min}$ infiltration rate experiments, the experimental observations and the numerical predictions also match up relatively well. For the lower infiltration rate experiments, the predicted bromide breakthrough curves lag slightly behind the experimentally obtained curves. This observation is consistent with the downward vadose zone transport via just a few fingers at these low flow rates, as shown in Figure 3.1 and Figure 3.5. The mean arrival times $\left(C / C_{o}=0.25\right)$ for the experiments are smaller than the predictions for the 1 - and $2-\mathrm{mL} / \mathrm{min}$ experiments (18 and 25 minutes, respectively) and about the same for the other three experiments (Table 3.1). Given that water flow and solute transport through fingers are not explicitly covered by the numerical model, the correspondence between the breakthrough curves shown in Figure 3.7 and the mean arrival times listed in Table 3.1 are remarkable. The agreement indicates that for the chosen infiltration rates, in combination with the hydraulic conductivity of the sand, continuum-based models produce reasonable agreement in terms of breakthrough behavior for the system modeled in the small flow cell, although large differences exist between the plume shapes in the unsaturated zone.

The infiltration experiments in the gravel showed more distinct finger development than in the sand. At the lowest flow rate $(1 \mathrm{~mL} / \mathrm{min})$ only one finger initially developed (Figure 3.8$)$ penetrating all the way to the capillary fringe, which was only approximately $1 \mathrm{~cm}$ for this porous medium. The arrival time of the single finger at the capillary fringe was 45 minutes, which is about two times faster than for the equivalent sand experiments. The simulated plume (Figure 3.9) for this flow rate showed a vertical penetration of only $15 \mathrm{~cm}$. Similar to what was observed for the sand experiments, increased infiltration rates resulted in more fingers, as can be seen in Figure 3.10 for the $25-\mathrm{mL} / \mathrm{min}$ experiment, but not nearly as many as for the equivalent experiments in sand. The arrival time of the fingers to the capillary fringe for this experiment was only 10 minutes. The numerical simulation results at the same time showed a plume that has almost reached the capillary fringe, although the width is much larger than observed experimentally (Figure 3.11). Over time, the fingers in all experiments branched out horizontally, as shown in Figure 3.12 and Figure 3.13 for the 1 - and $25-\mathrm{mL} / \mathrm{min}$ experiments, approximately at the time dye breakthrough from the flow cell took place.

The experimental and simulated bromide breakthrough curves for the transport experiments in the gravel are shown in Figure 3.14. For this porous medium, the experimentally observed bromide breakthrough started before the numerically predicted breakthrough for all experiments. The main reason for the larger decrepancies was the more limited number of fingers that formed in the more conductive gravel, compared to the sand, for the same infiltration rate. As a result, the cross-sectional areas in the gravel experiments were smaller, resulting in a more rapid transport of water through the gravel and generally faster plume arrival times. For this porous medium, the numerical model overpredicted the plume arrival times for all experiments (Table 2.1), even for the $25-\mathrm{mL} / \mathrm{min}$ experiment. Even at this rate, the hydraulic conductivity was not exceeded, leading to unstable displacements. 


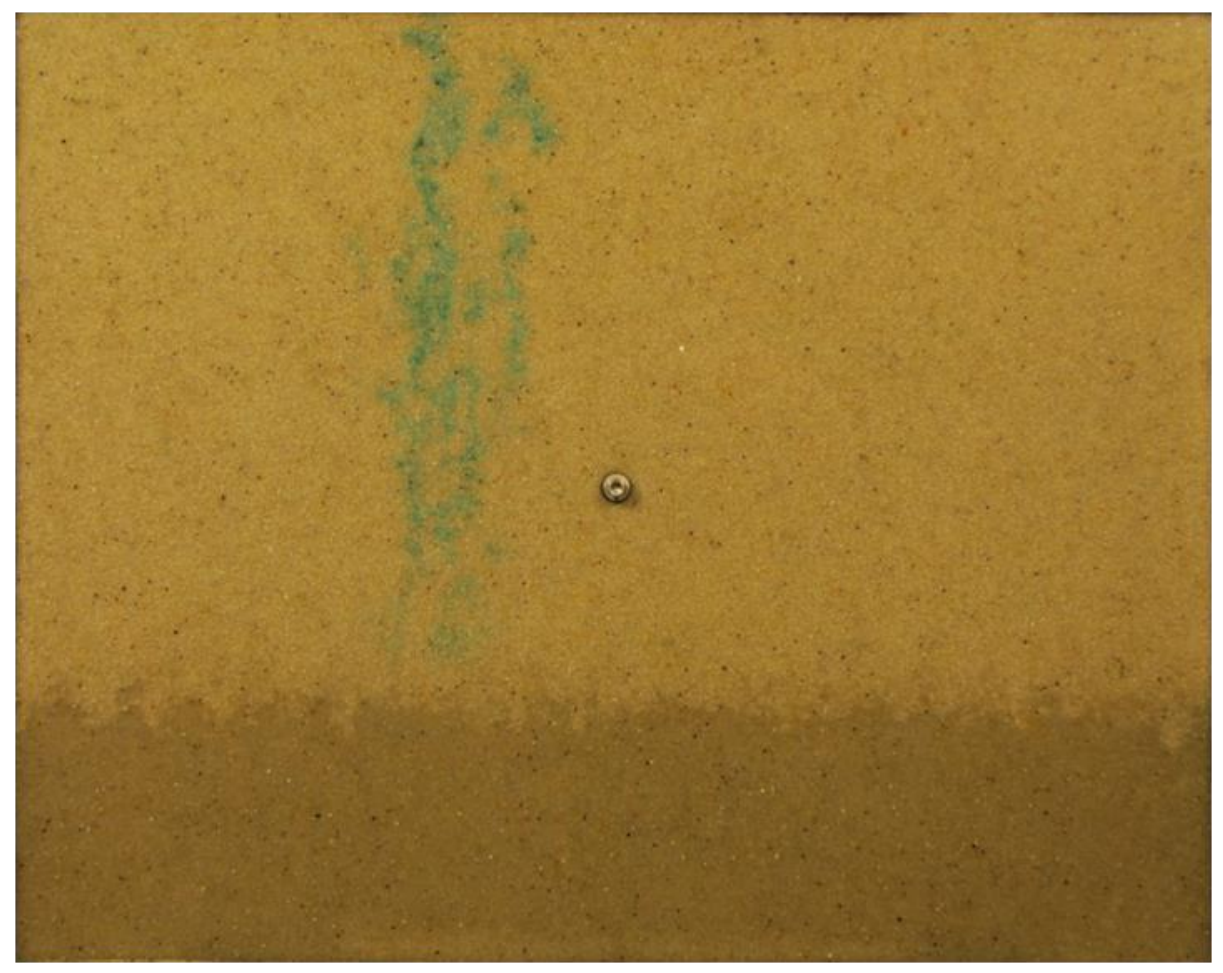

Figure 3.1. Plume development after 90 minutes for experiment Sa-1.

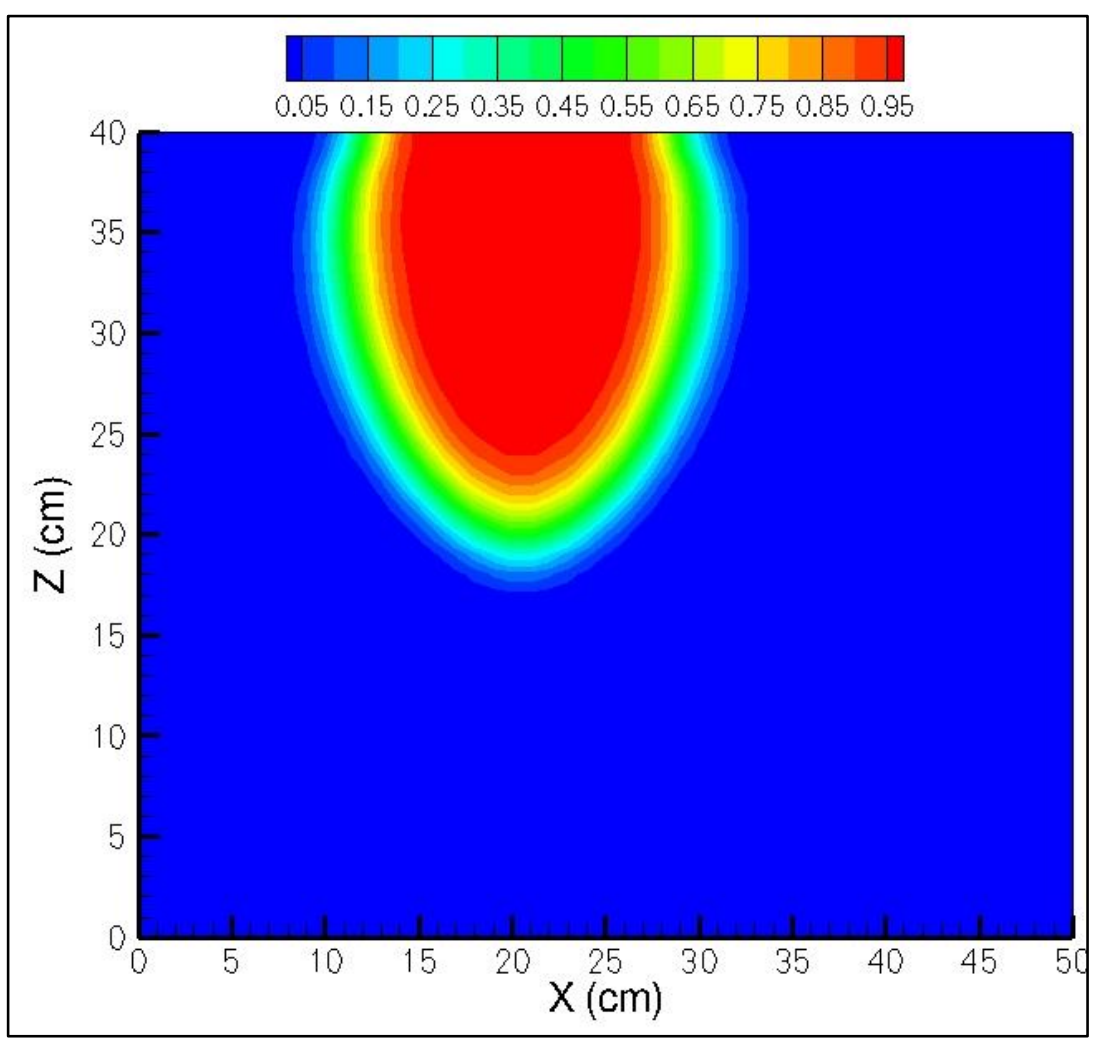

Figure 3.2. Simulated plume development after 90 minutes for experiment Sa-1. 


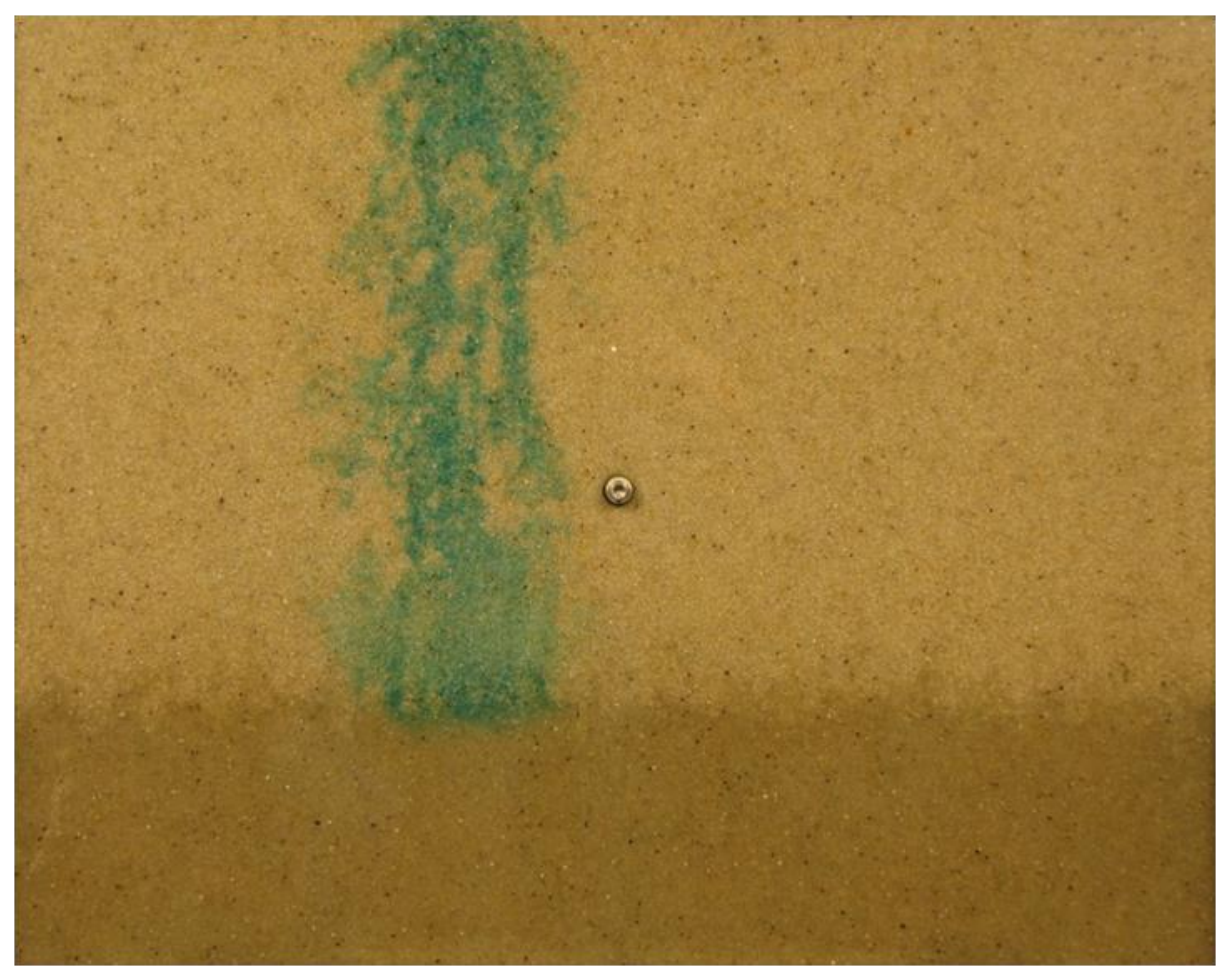

Figure 3.3. Plume development after 10 minutes for experiment $\mathrm{Sa}-25$.

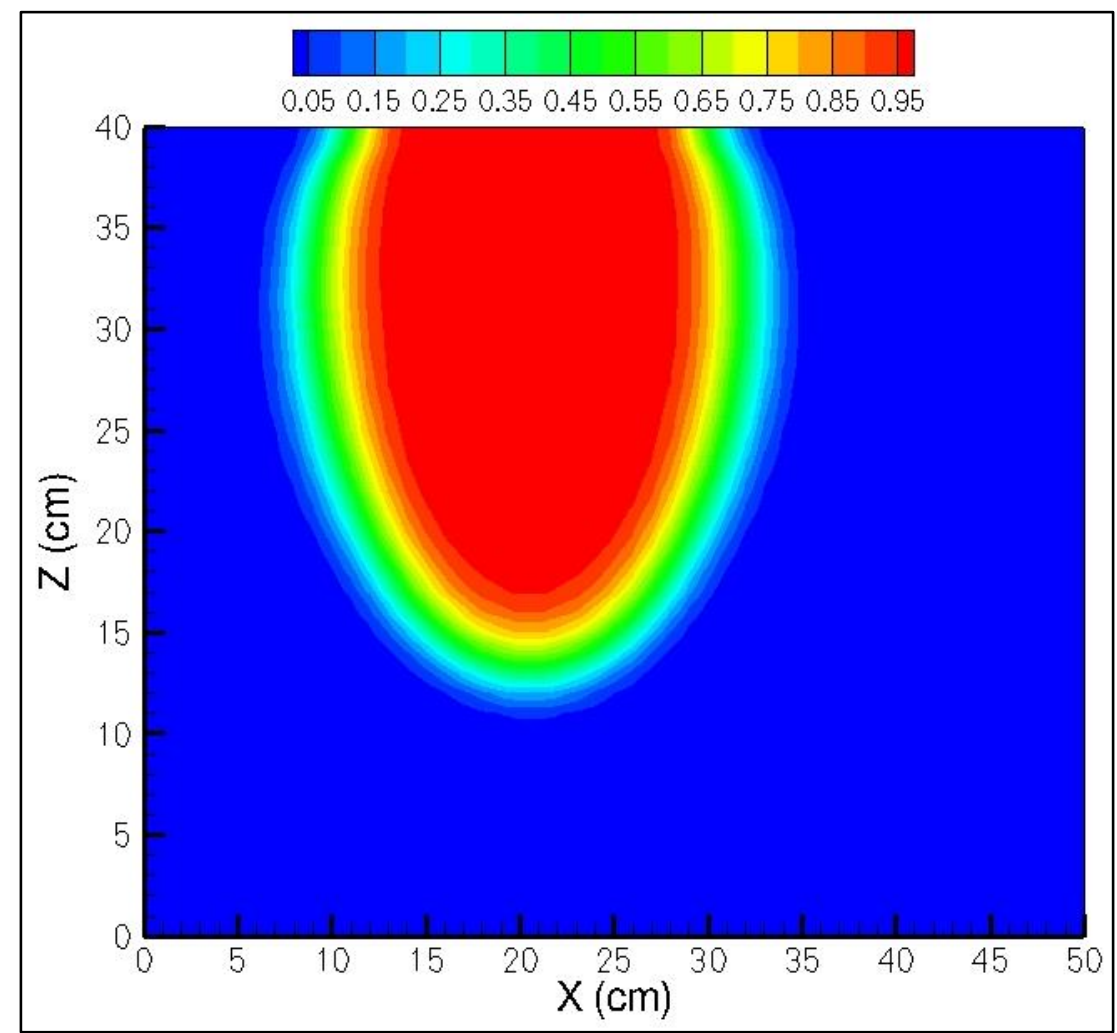

Figure 3.4. Simulated plume development after 10 minutes for experiment Sa-25. 


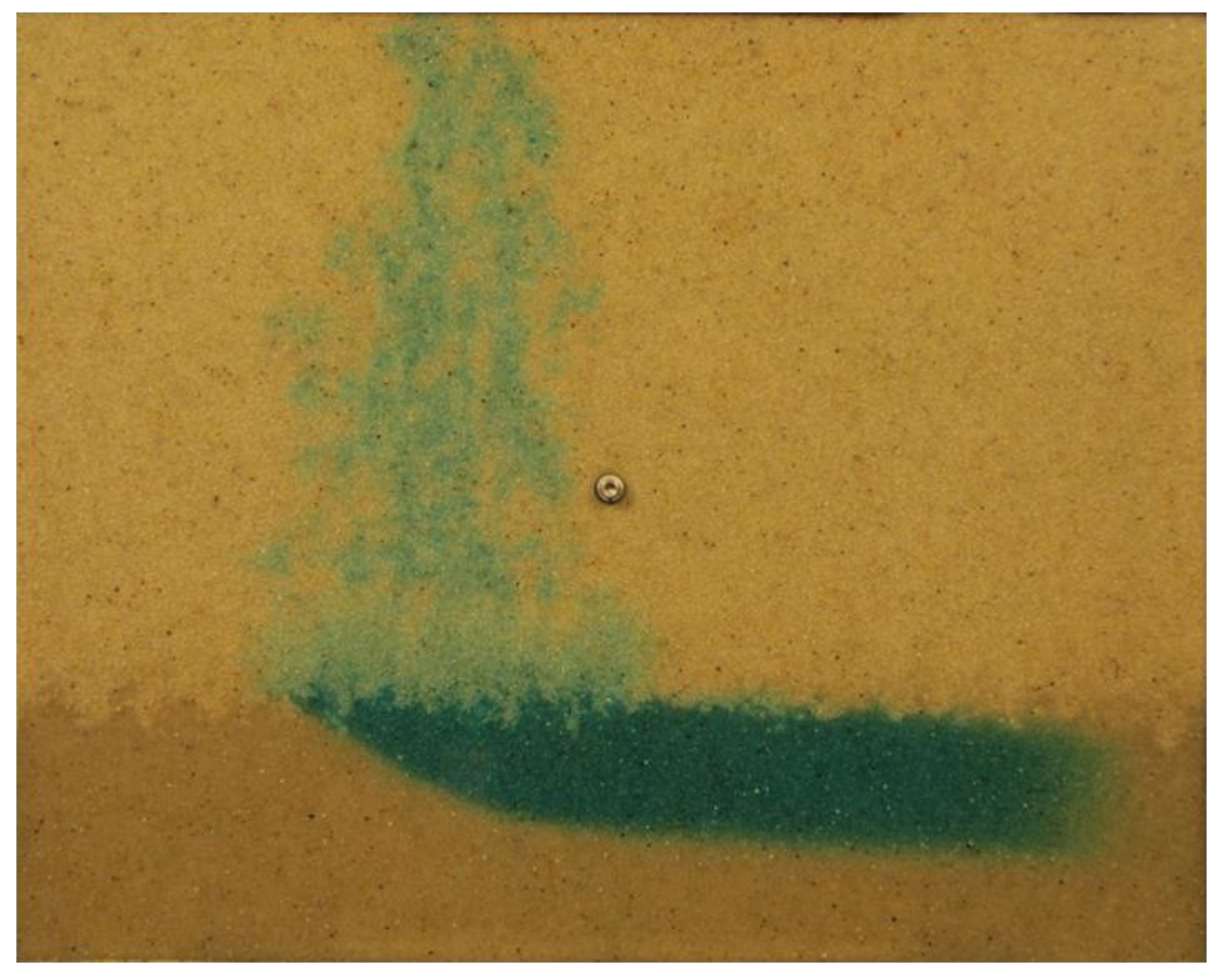

Figure 3.5. Plume development after 320 minutes for experiment Sa-1.

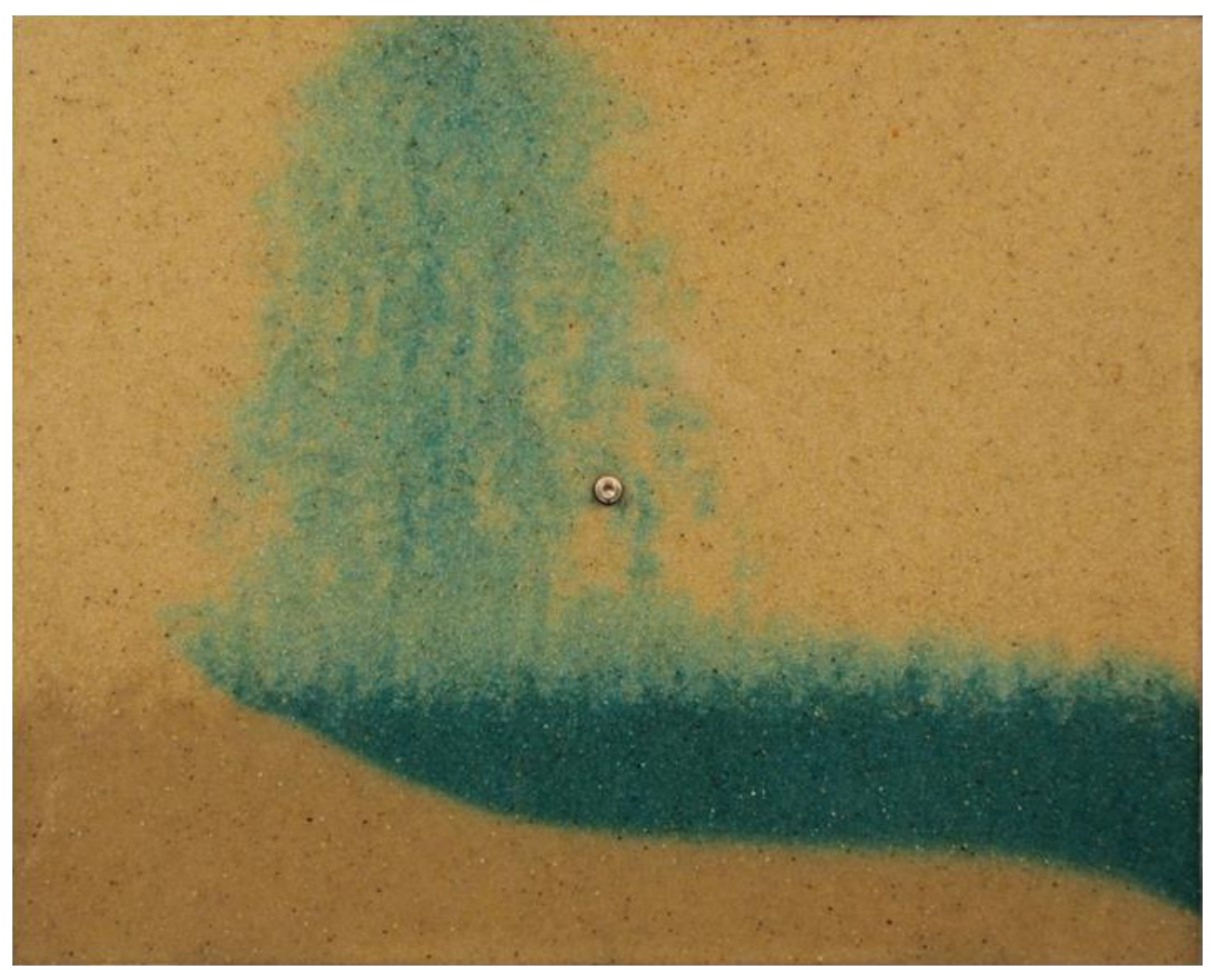

Figure 3.6. Plume development after 18 minutes for experiment Sa-25. 


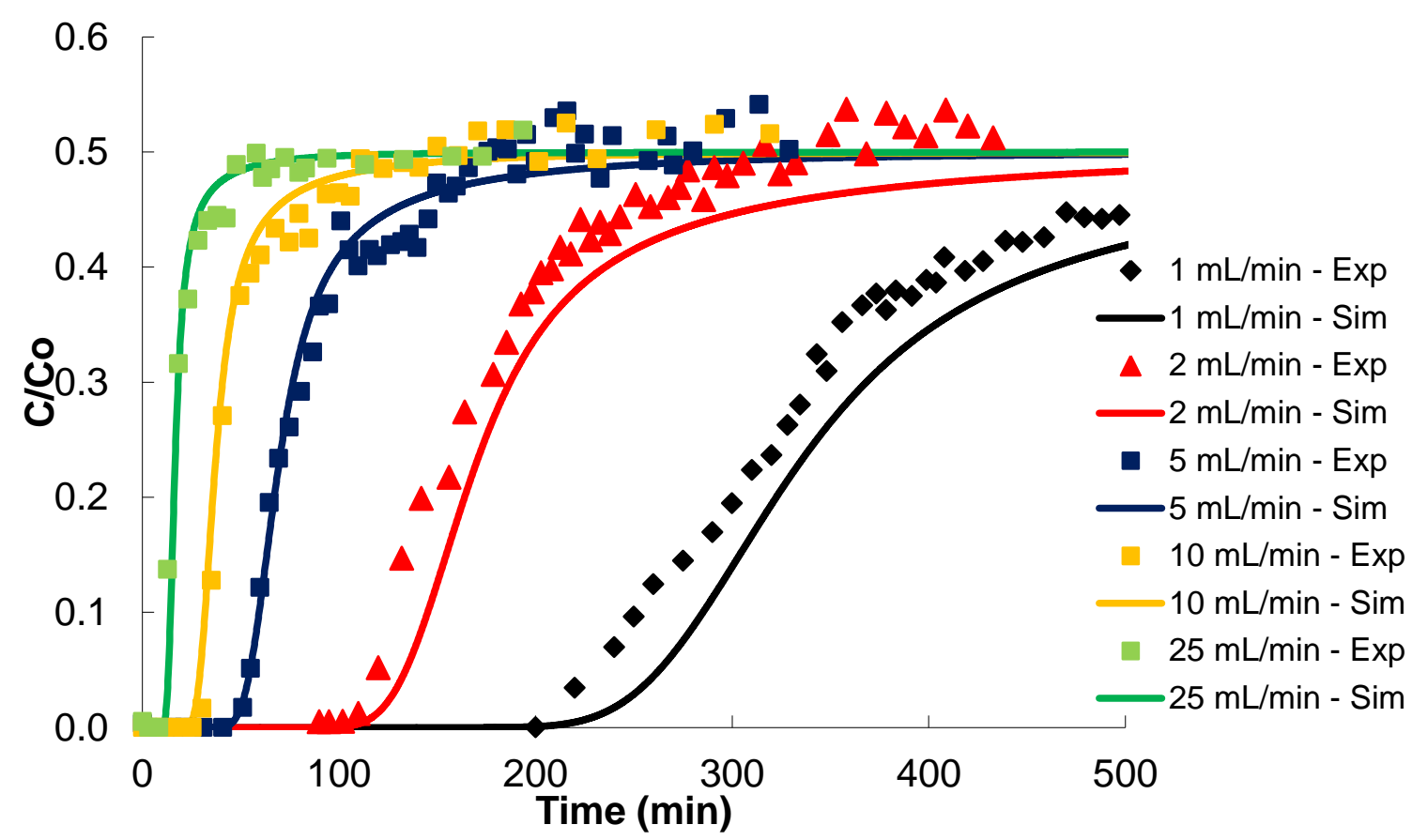

Figure 3.7. Experimental and simulated bromide breakthrough curves for the transport experiments in 12/20-mesh sand.

Table 3.1. Simulated and experimentally observed arrival times $\left(C / C_{0}=0.25\right.$; minutes $)$ for the experiments conducted in Hanford Lysimeter Gravel and 12/20-mesh sand.

\begin{tabular}{ccccc}
\hline \multirow{2}{*}{$\begin{array}{c}\text { Injection Rate } \\
(\mathrm{mL} / \mathrm{min})\end{array}$} & $\begin{array}{c}\text { Experimental } \\
\text { Arrival Time } \\
(\mathrm{min})\end{array}$ & $\begin{array}{c}\text { Numerical } \\
\text { Arrival Time } \\
(\mathrm{min})\end{array}$ & $\begin{array}{c}\text { Experimental } \\
\text { Arrival Time } \\
(\mathrm{min})\end{array}$ & $\begin{array}{c}\text { Numerical Arrival } \\
\text { Time }(\mathrm{min})\end{array}$ \\
\hline 1 & 253 & 298 & 325 & 343 \\
2 & 131 & 149 & 162 & 187 \\
5 & 32 & 62 & 72 & 71 \\
10 & 14 & 31 & 40 & 38 \\
25 & 7 & 13 & 17 & 17 \\
\hline
\end{tabular}




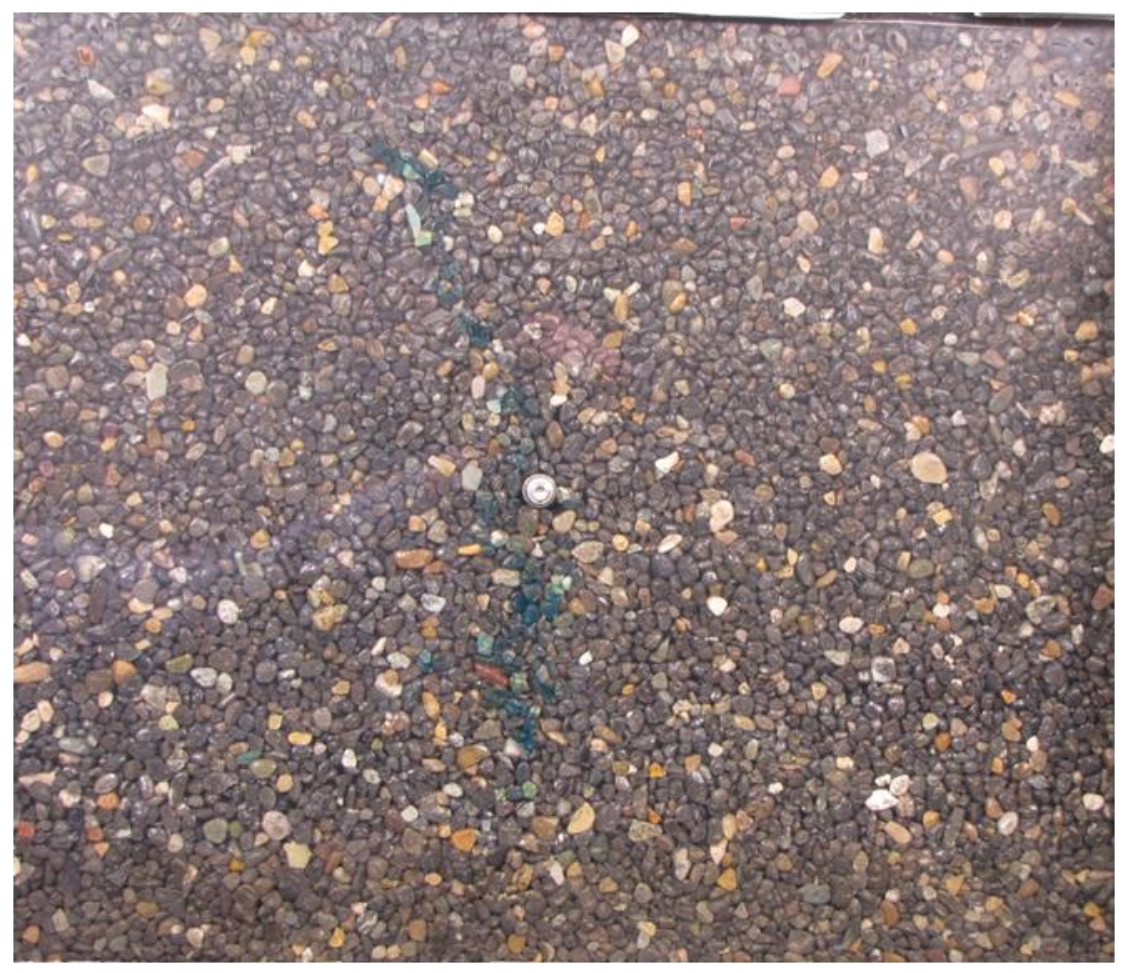

Figure 3.8. Plume development after 45 minutes for experiment Gr-1.

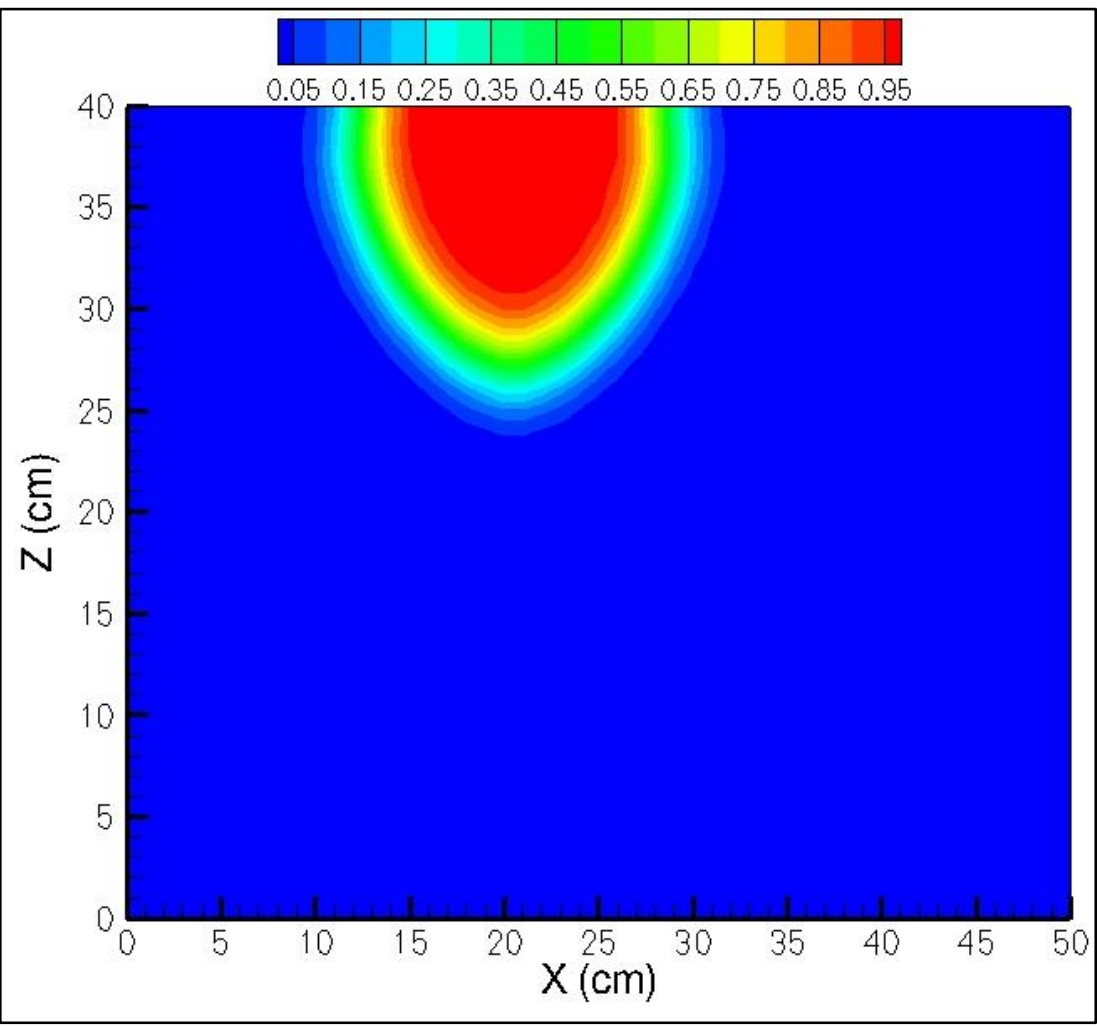

Figure 3.9. Simulated plume development after 45 minutes for experiment Gr-1. 


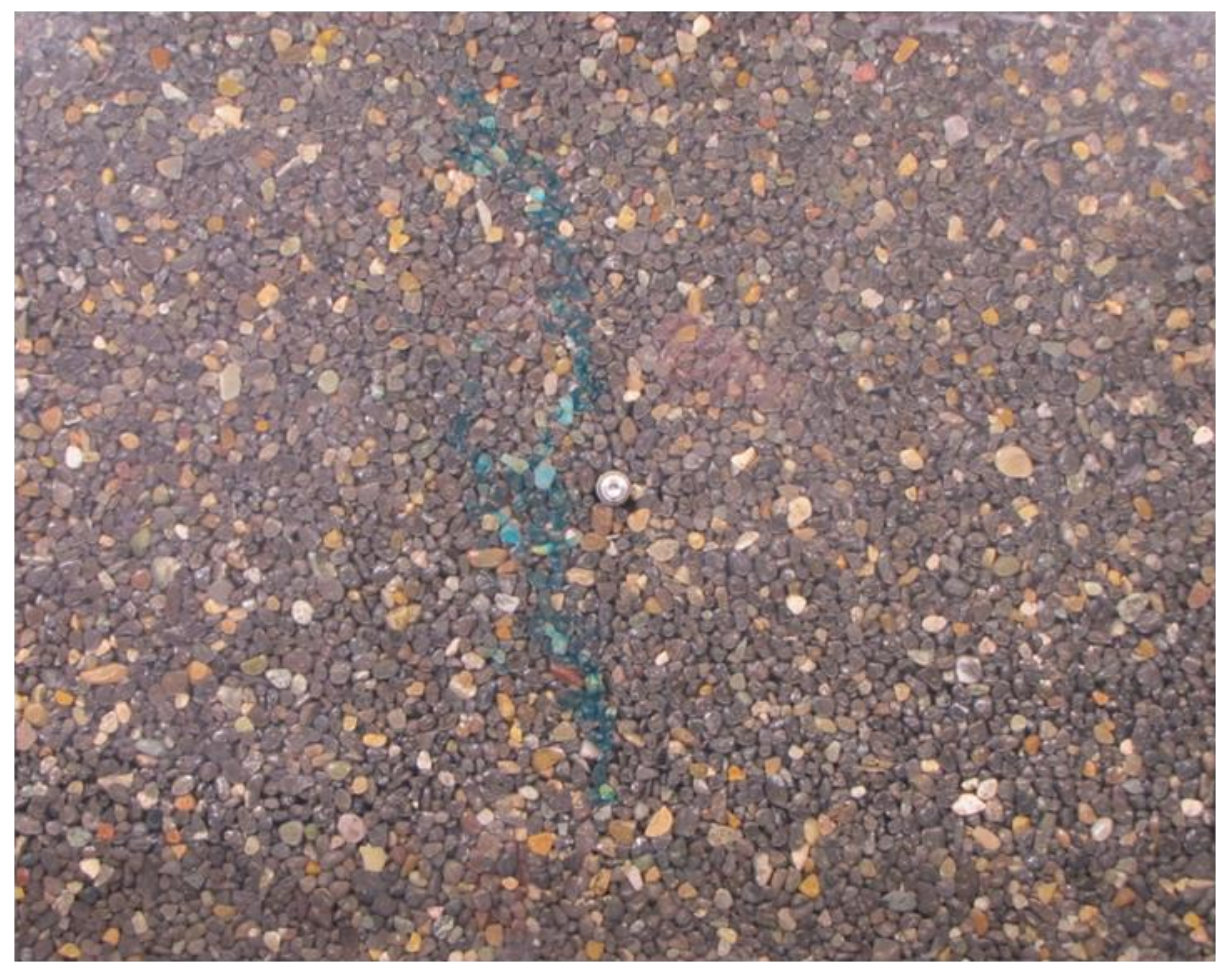

Figure 3.10. Plume development after 10 minutes for experiment Gr-1.

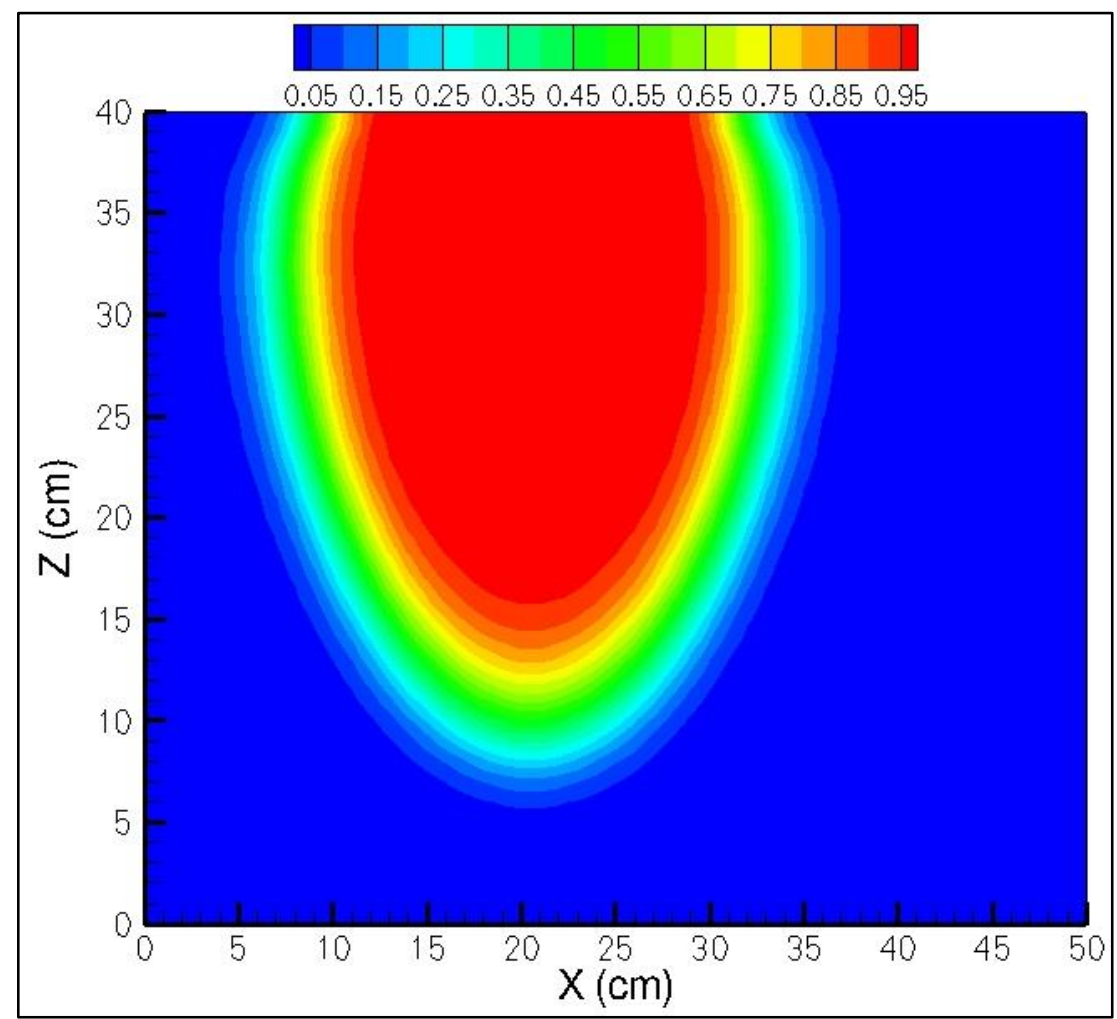

Figure 3.11. Simulated plume development after 10 minutes for experiment Gr-25. 


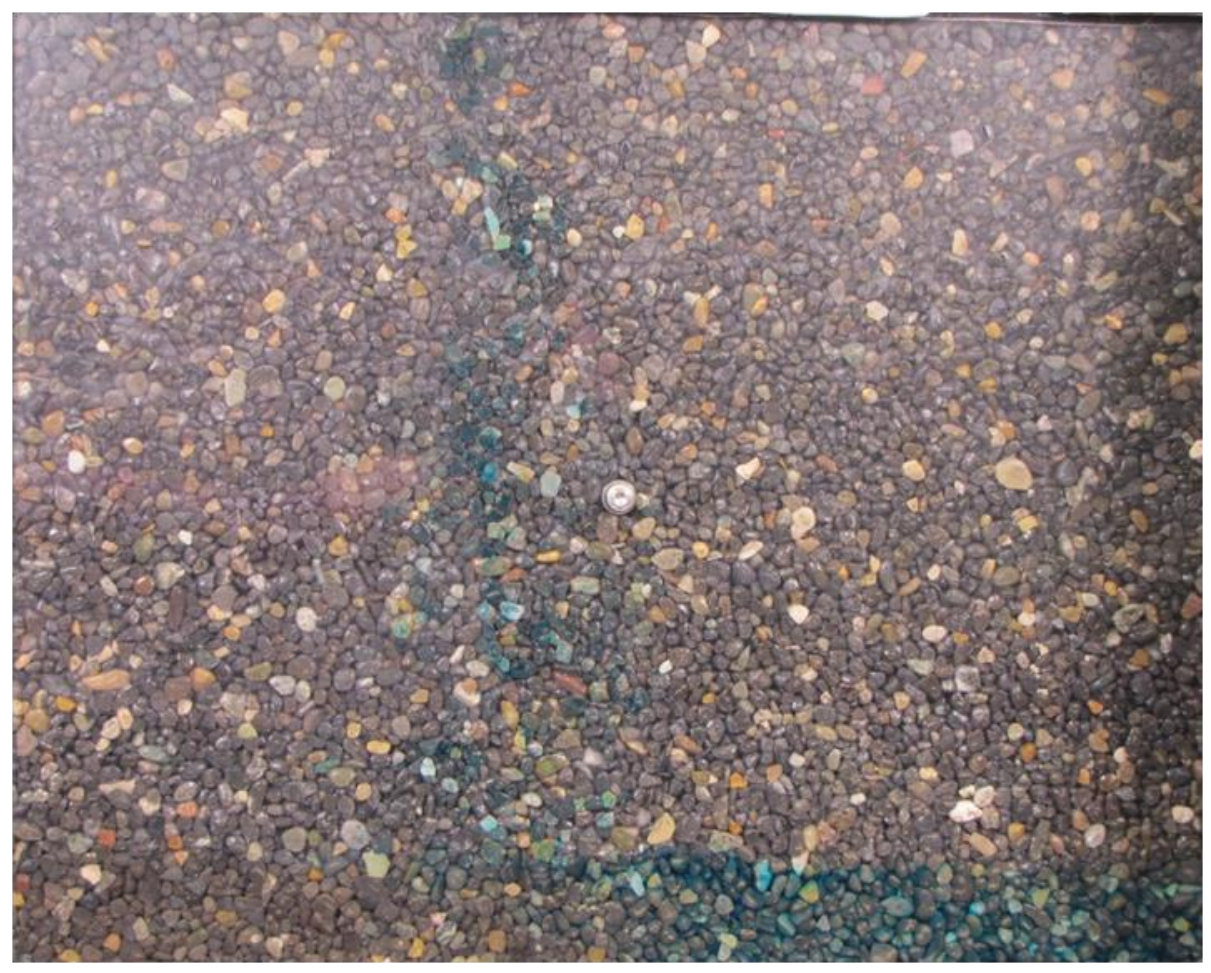

Figure 3.12. Plume development after 250 minutes for experiment Gr-1.

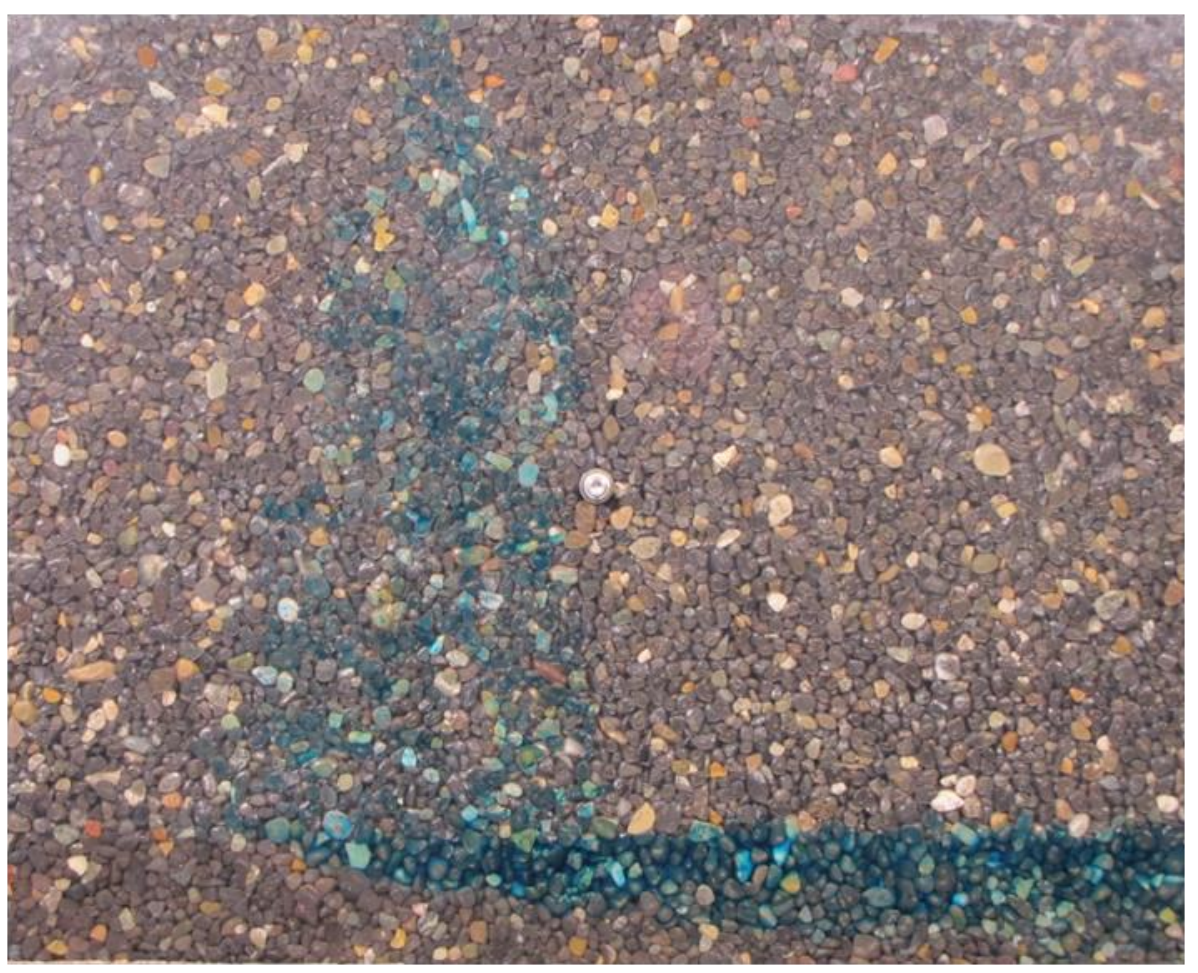

Figure 3.13. Plume development after 20 minutes for experiment Gr-25. 


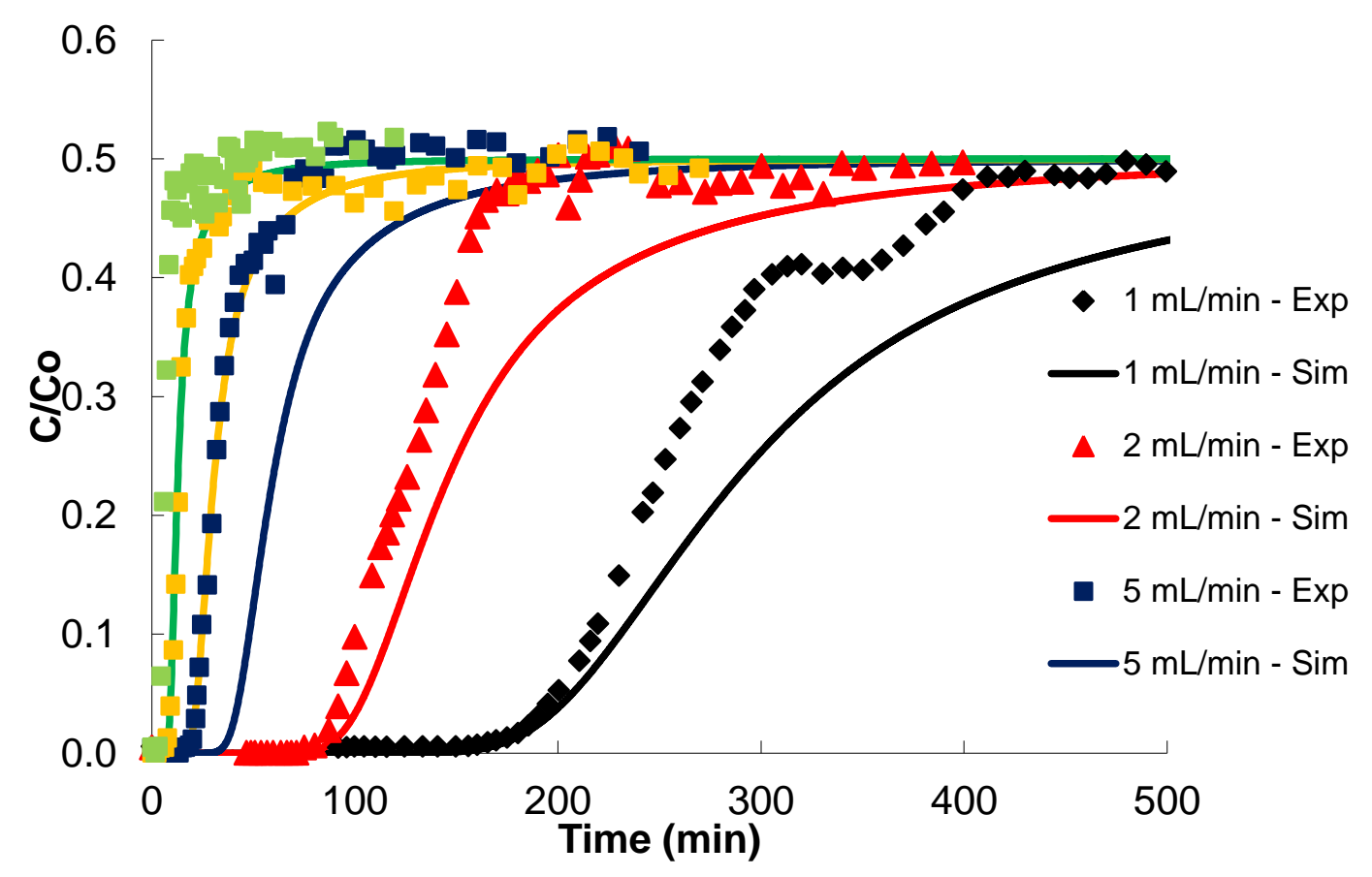

Figure 3.14. Experimental and simulated bromide breakthrough curves for the transport experiments in Hanford Lysimeter Gravel.

\subsection{Large Flow Cell Experiments}

A total of four large flow cell experiments, two short duration, fast leak experiments (Exp. F-1 and Exp. F-2) and two long duration, slow leak experiments (Exp. S-1 and Exp. S-2), were conducted (Table 2.1). Pictures of the plumes for the two short duration, fast leak experiments are shown in Figure 3.15 and Figure 3.16 for Exp. F-1 and F-2, respectively. The experimentally obtained and simulated breakthrough curves for these experiments are shown in Figure 3.17. Pictures of the plumes for the two long duration, slow leak experiments are shown in Figure 3.18 and Figure 3.19 for Exp. S-1 and S-2, respectively. The experimentally obtained and simulated breakthrough curves for these experiments are shown in Figure 3.20.

The plumes for the short duration, fast leak experiments moved rapidly through the unsaturated zone. In both experiments, the dye arrived at the capillary fringe, located in the $\mathrm{H} 3 \mathrm{Gravel}$, in less than 10 hours, despite a spill size of $90 \mathrm{~cm}^{3}$. The plume for the slower injection rate experiment (Exp. F-2) migrated only marginally slower (Figure 3.16) than the plume for the faster injection rate (Figure 3.15). The fact that the same volume was injected over double the time did not considerably alter the shape of the plume. Both plumes were not affected by the interfaces between the gravels and the sand, indicating that capillary barrier effects were not apparent. The plume width for experiments was always less than the width of the flow cell, with maximum widths of $15 \mathrm{~cm}$ in Exp. F-1 and $16 \mathrm{~cm}$ in Exp. F-2. After arriving at the capillary fringe, the plumes were diverted toward the outlet in thin layers, with an approximate thickness of $3 \mathrm{~cm}$, on top of the capillary fringe. The actual plumes from these experiments never migrated below the water table. Consistent with the visual observations of the plume behavior, the breakthrough curves (Figure 3.17) show only marginal differences between the two experiments. The 
plot also clearly indicates that the numerical simulations provide reasonable matches between the effluent concentration behavior. The satisfactory match between experimental observation and numerical predictions is a result of the well-defined boundary and initial conditions, independent determination of the hydraulic properties, the relative simplicity of the model, and the lack of the formation of unstable fingers, as observed in the small flow cell experiments. Figure 3.17 also shows that the maximum concentrations in both experiments are less than $1 \%$ of the leak bromide concentration, indicating considerable dilution in the saturated zone. In addition, the plots show a considerable tailing. At the end of the experiments, a mass balance showed that less than $8 \%$ of the injected bromide mass had been recovered in both experiments, indicating that the majority of the bromide was still present in the unsaturated zone.

The long duration, slow leak experiments resulted in much wider plumes compared to the short duration, fast leak experiments (Figure 3.18 and Figure 3.19). The travel times through the unsaturated zone to the capillary fringe were considerably longer; the capillary fringe arrival times of the red dye were approximately 6 days for Exp. S-1 and 8 days for Exp. S-2. Although the injection rate for Exp. S-2 was half of the rate imposed for Exp. S-1, the travel time through the flow cell was not a factor of two times slower due to the lateral movement as a result of capillary action. As for the short duration, fast leak experiments, the interfaces between the gravels and sand did not have an obvious effect on the movement of the dye plumes. In both slow rate experiments, the width of the plumes was considerably larger than the width for the fast rate experiments due to the increased relative importance of capillarity in this system where water in the unsaturated zone moved considerably slower. The maximum widths for Exp. S-1 and S-2 were 33 and $35 \mathrm{~cm}$, respectively.

Because the injection of the water containing the dye and bromide was continuous, the resulting breakthrough curves show a continuous increase until the maximum $\mathrm{C} / \mathrm{C}_{\mathrm{o}}$ value was asymptotically reached (Figure 3.20). The maximum dimensionless concentration for each experiment is the ratio of the source injection rate divided by the total flow rate in the groundwater, which is approximately 0.02 for Exp. S-1 and 0.01 for Exp. S-2. In terms of effluent arrival times $(\mathrm{C} / \mathrm{Co}=0.01$ for Exp. $\mathrm{S}-1$ and $\mathrm{C} / \mathrm{Co}=$ 0.005 for Exp. S-2), the bromide arrived at the outlet after 6.8 days for Exp. S-1 and 9.1 days for Exp. $\mathrm{S}-2$. For both experiments, it means that the travel times through the groundwater added approximately 1 day to the observed dye arrival times at the capillary fringe (Figure 3.18 and Figure 3.19). In both of the long duration, slow flow experiments, no fingering was observed because the slow injection rates did not allow for any viscous fingers to develop. For these kinds of infiltration experiments in materials of relatively low permeability, the capillary forces tend to dominate the viscous forces. Similar to the short duration, fast rate experiments, the simulator predicted the breakthrough behavior of the bromide reasonably well. The predicted and observed maximum concentrations were relatively close, as were the observed and simulated times for these concentrations to occur. As for the faster experiments in the large flow cell, the satisfactory agreement observed in the small flow cell experiments is a result of the welldefined boundary and initial conditions, independent determination of the hydraulic properties, the relative simplicity of the model, and the lack of the formation of unstable fingers. 


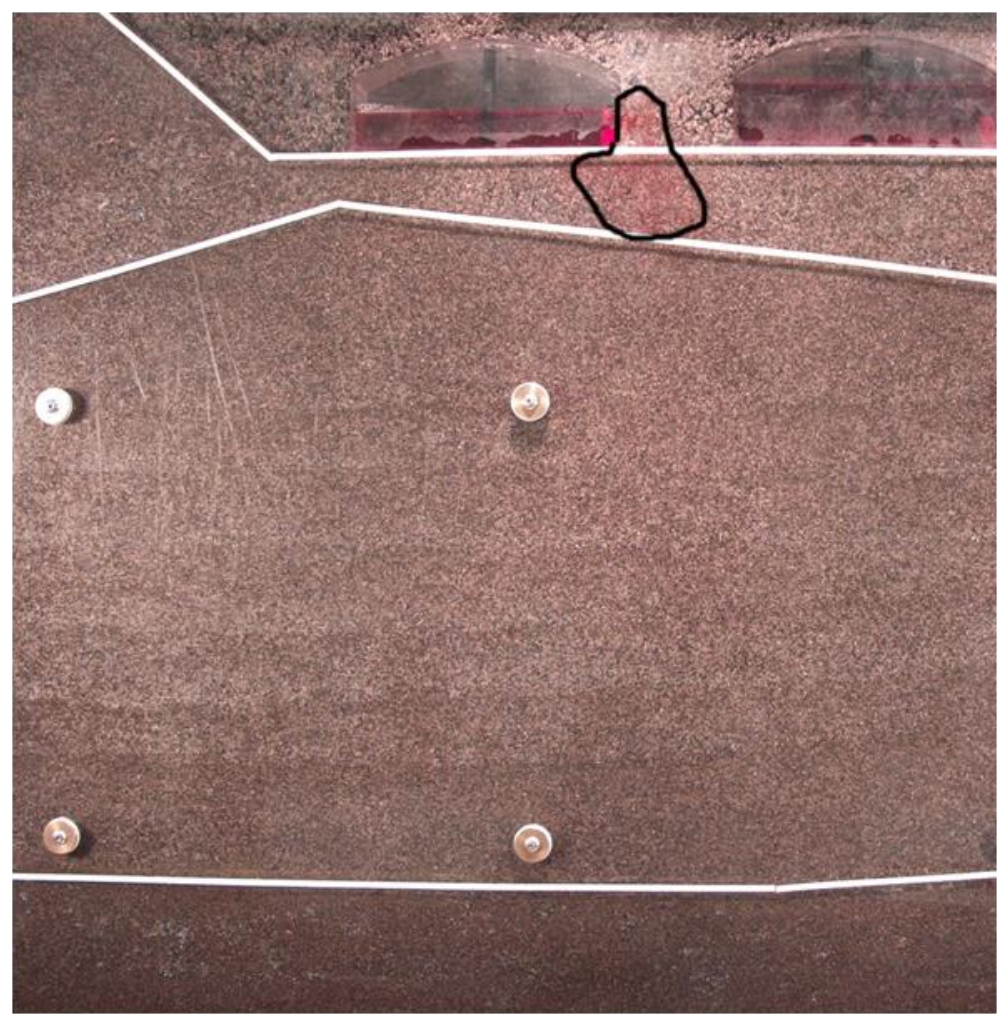

(a)

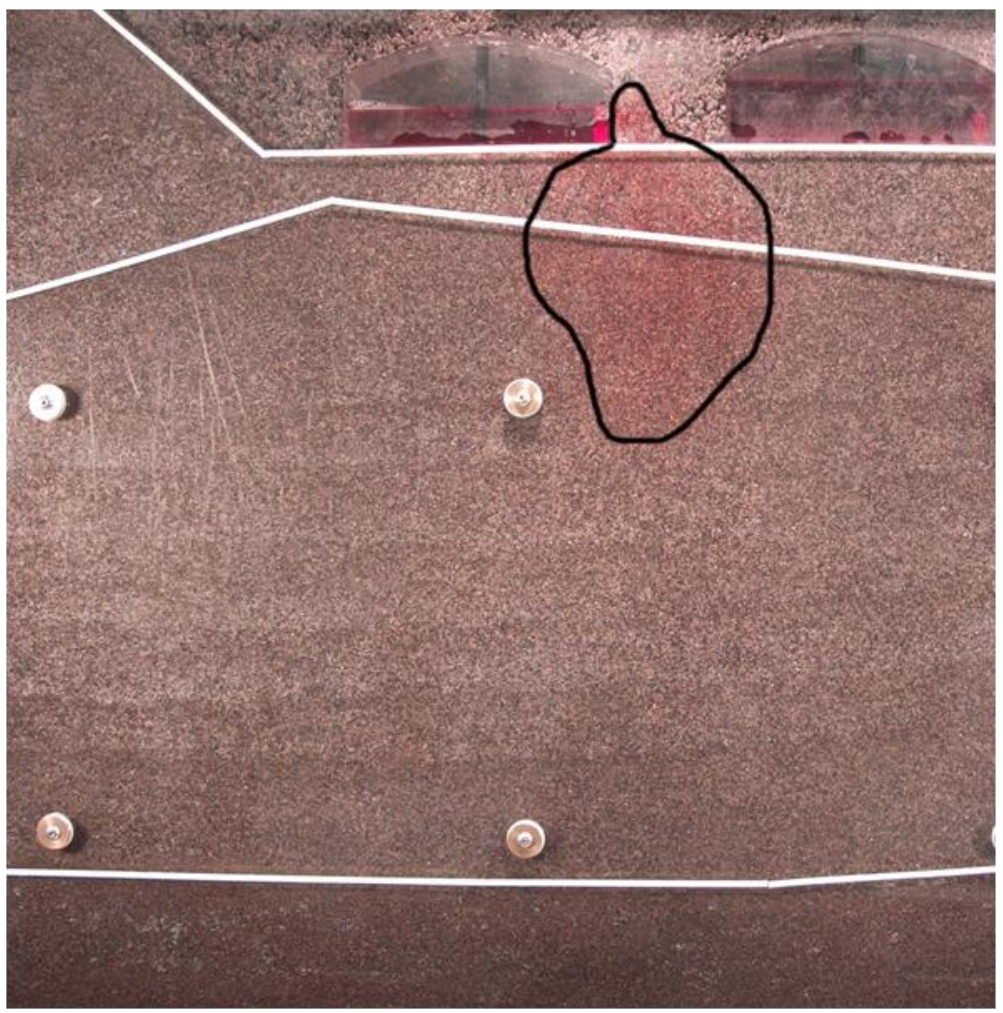

(b)

Figure 3.15. Dye distribution for Exp. F-1 (a) 1, (b) 4, (c) 8, and (d) 12 hours after start of injection. The injection rate was $1 \mathrm{~mL} / \mathrm{min}$ and the injection duration was 90 minutes. 

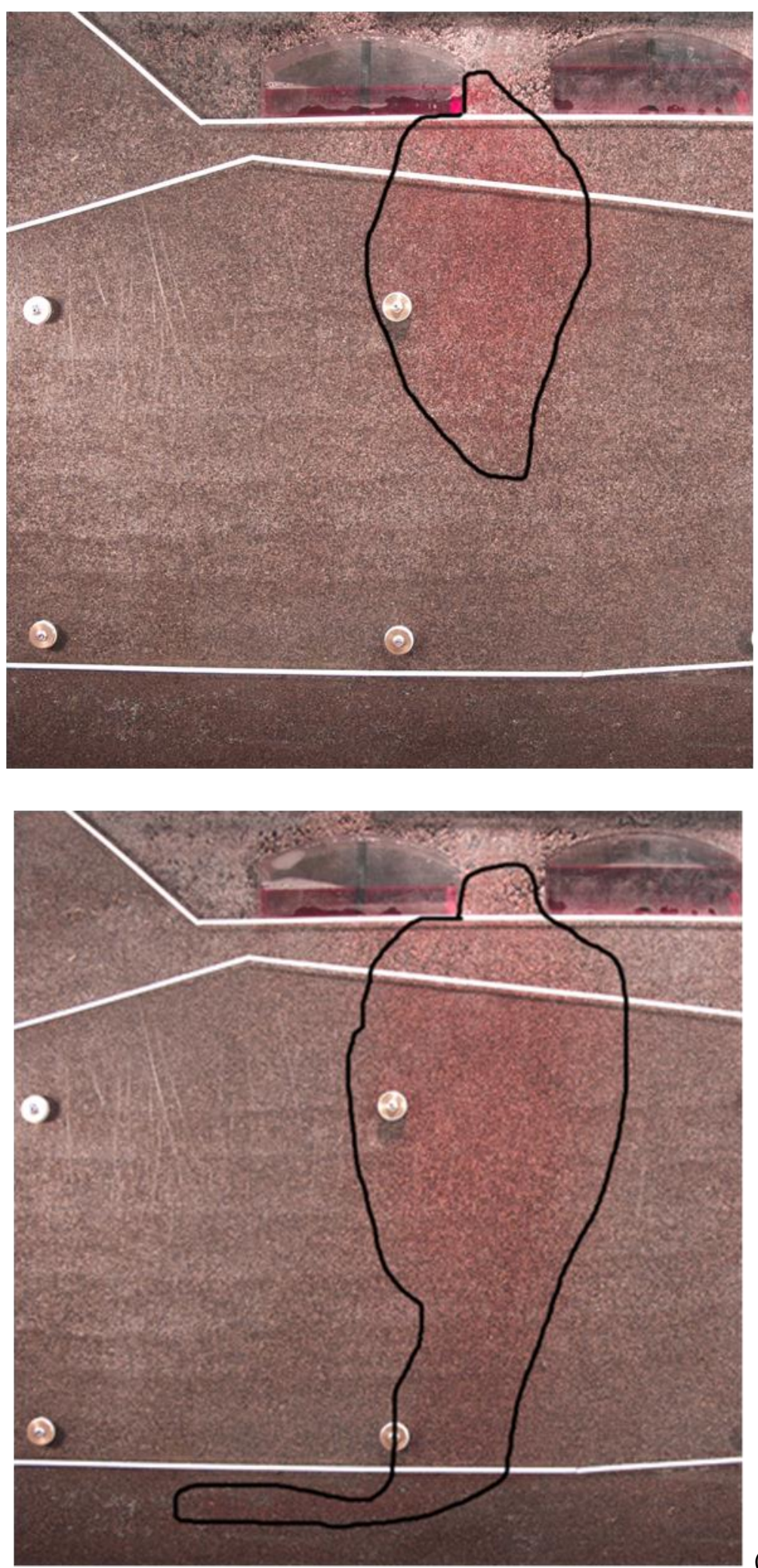

(d)

Figure 3.15. (contd) 


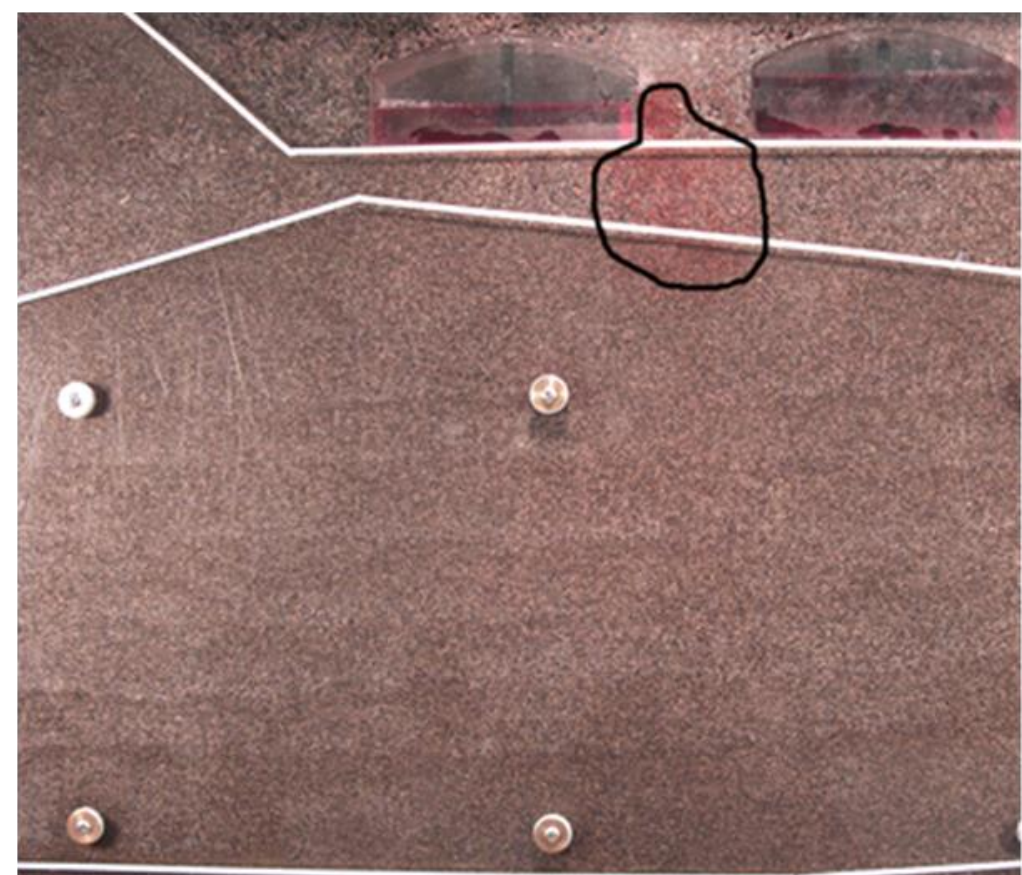

(a)

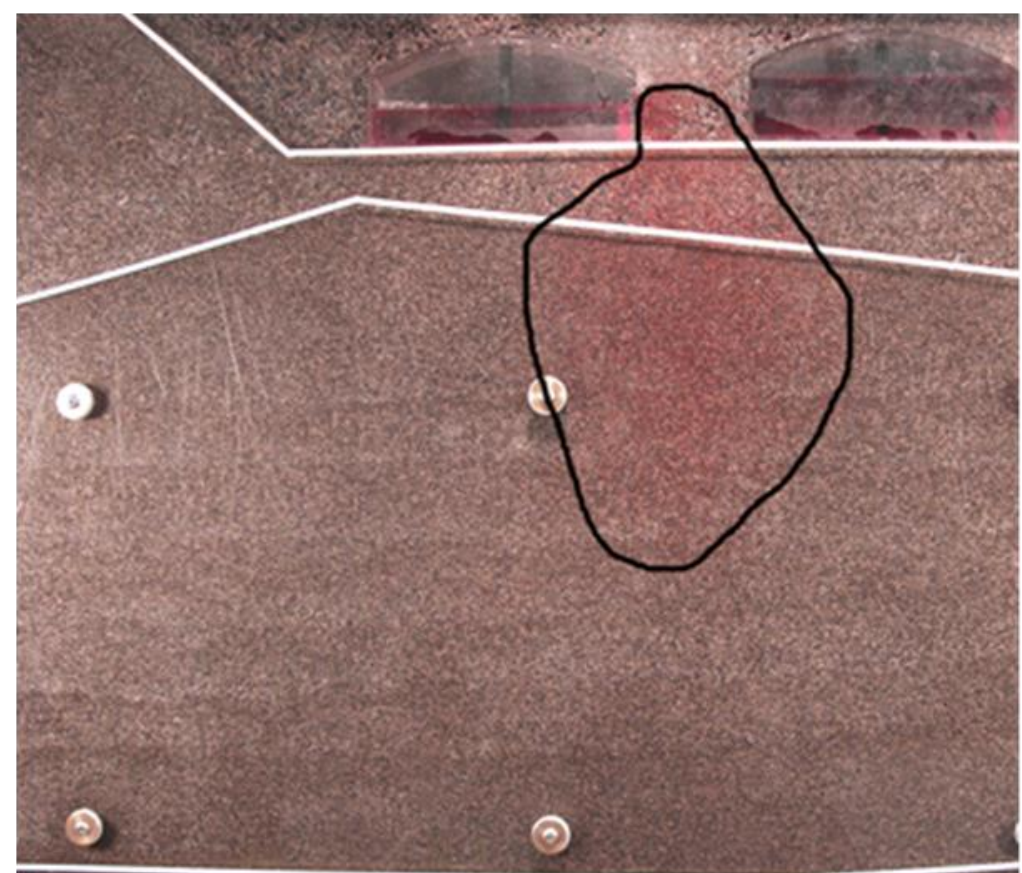

(b)

Figure 3.16. Dye distribution for Exp. F-1 (a) 3, (b) 6, (c) 10, and (d) 14 hours after start of injection. The injection rate was $0.5 \mathrm{~mL} / \mathrm{min}$ and the injection duration was 180 minutes. 

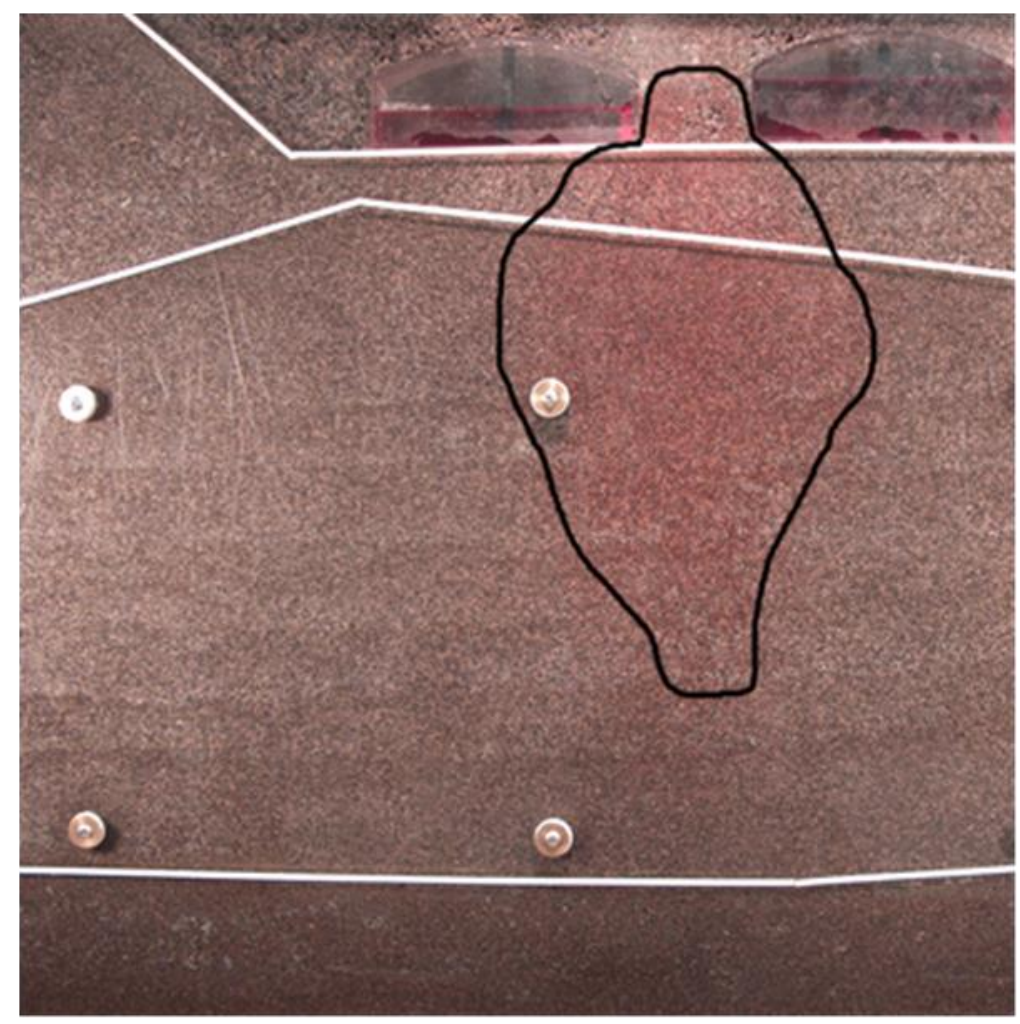

(c)

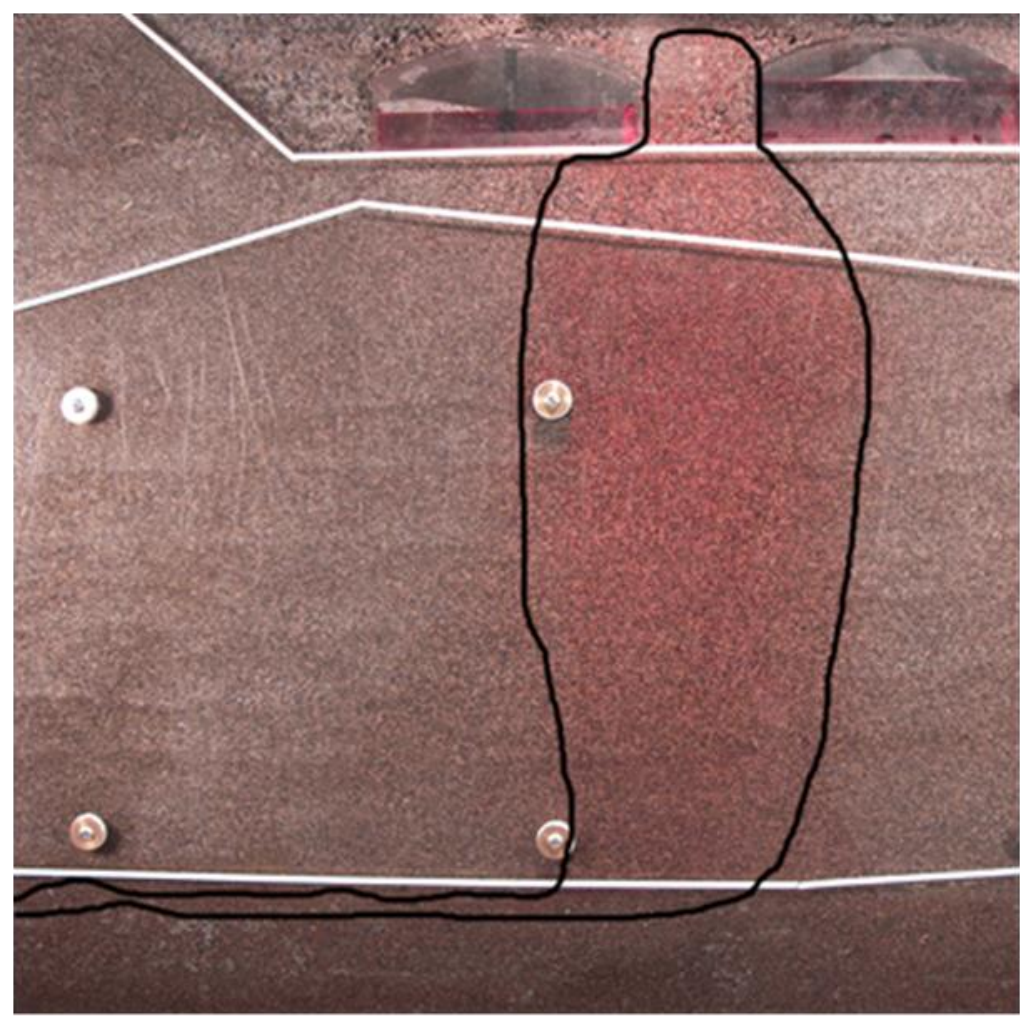

(d)

Figure 3.16. (contd) 


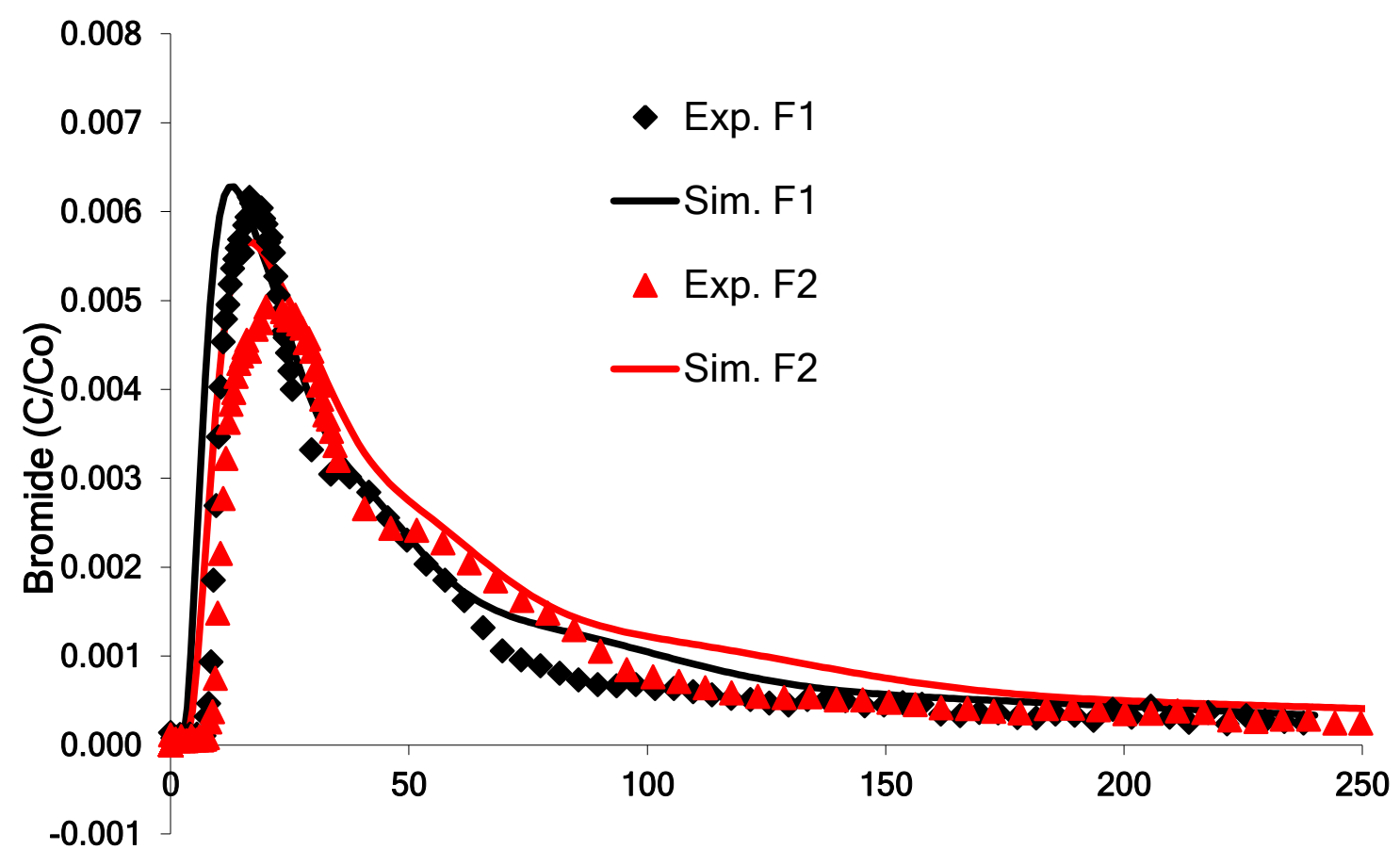

Time (hr)

Figure 3.17. Measured and simulated normalized bromide concentrations as a function of time for Exp. F-1 and F-2. 

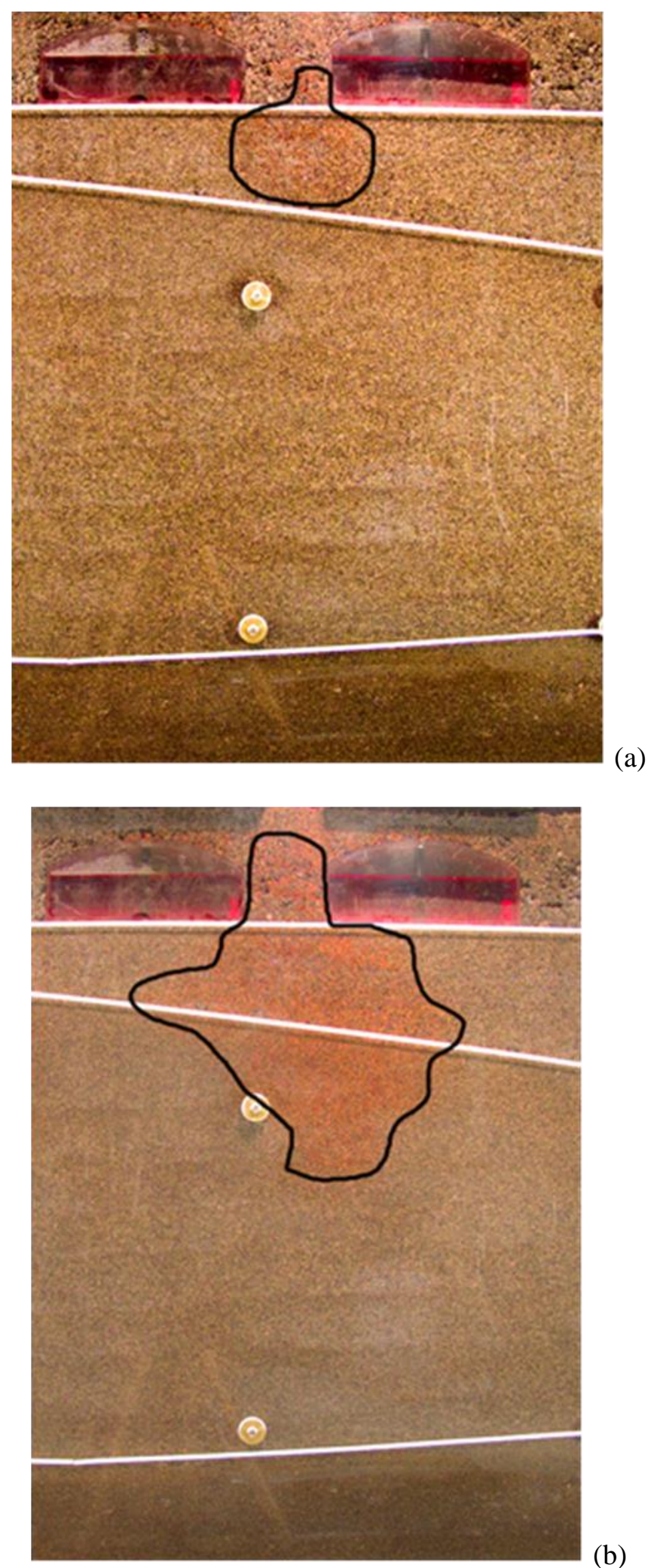

(b)

Figure 3.18. Dye distribution for Exp. S-1 (a) 0.5, (b) 3, (c) 5, and (d) 7 days after start of injection. The injection rate was $0.04 \mathrm{~mL} / \mathrm{min}$. 


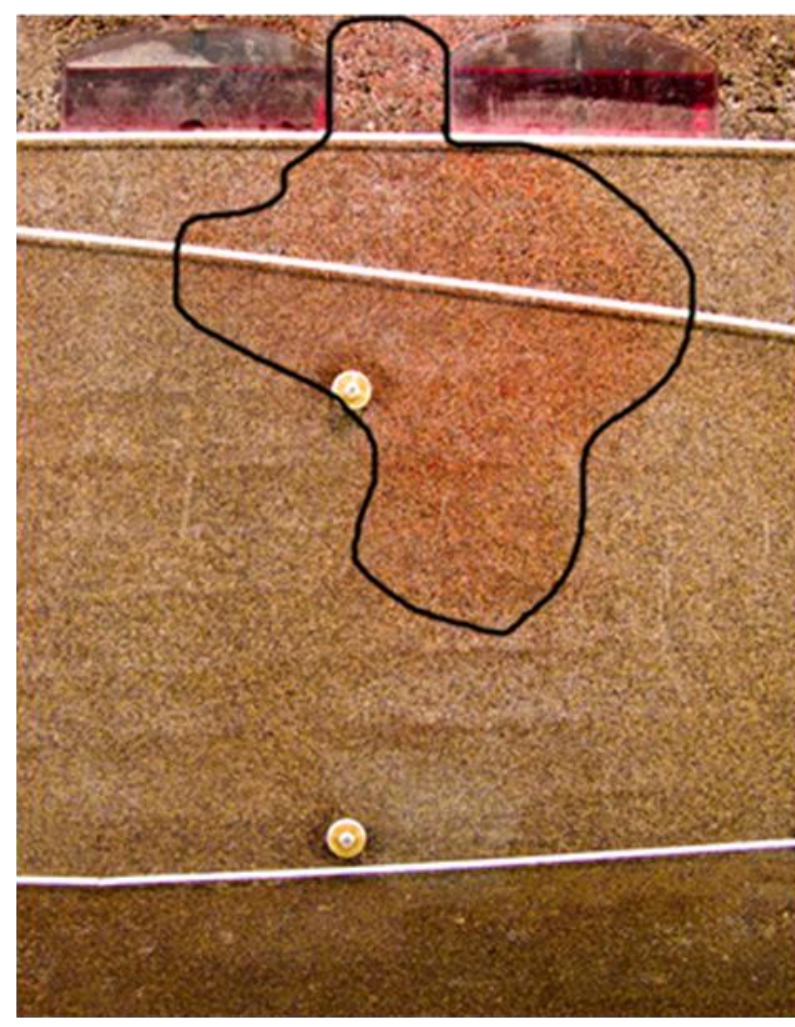

(c)

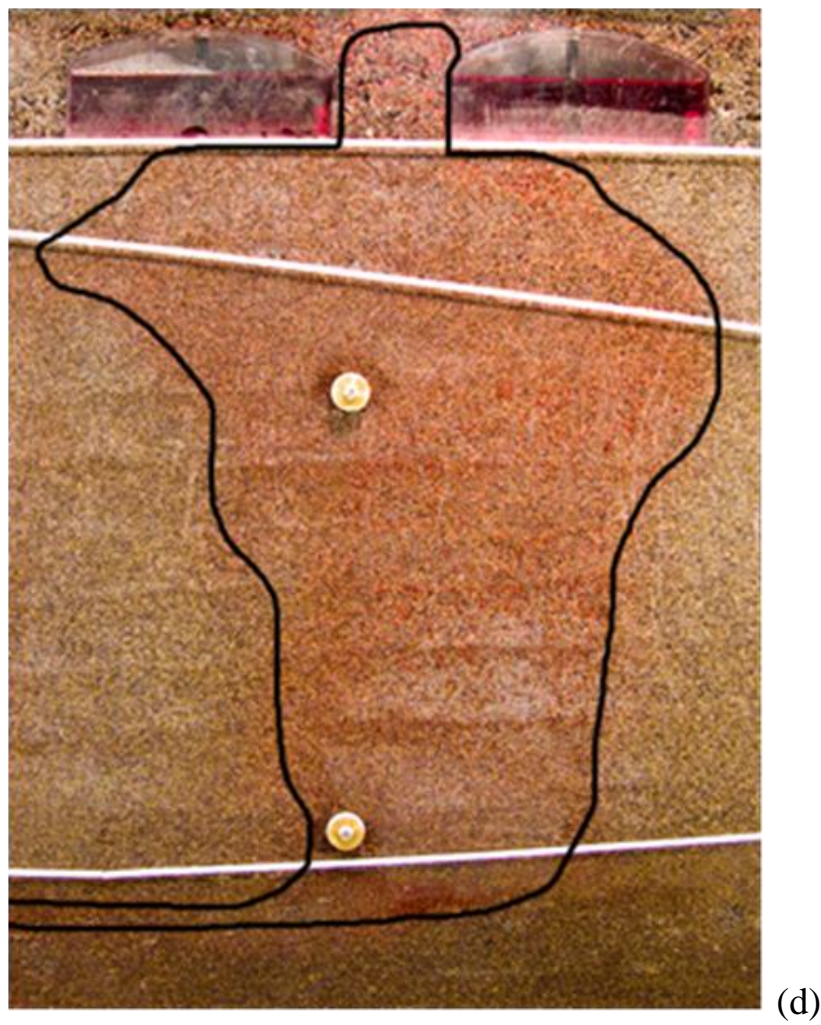

Figure 3.18. (contd) 

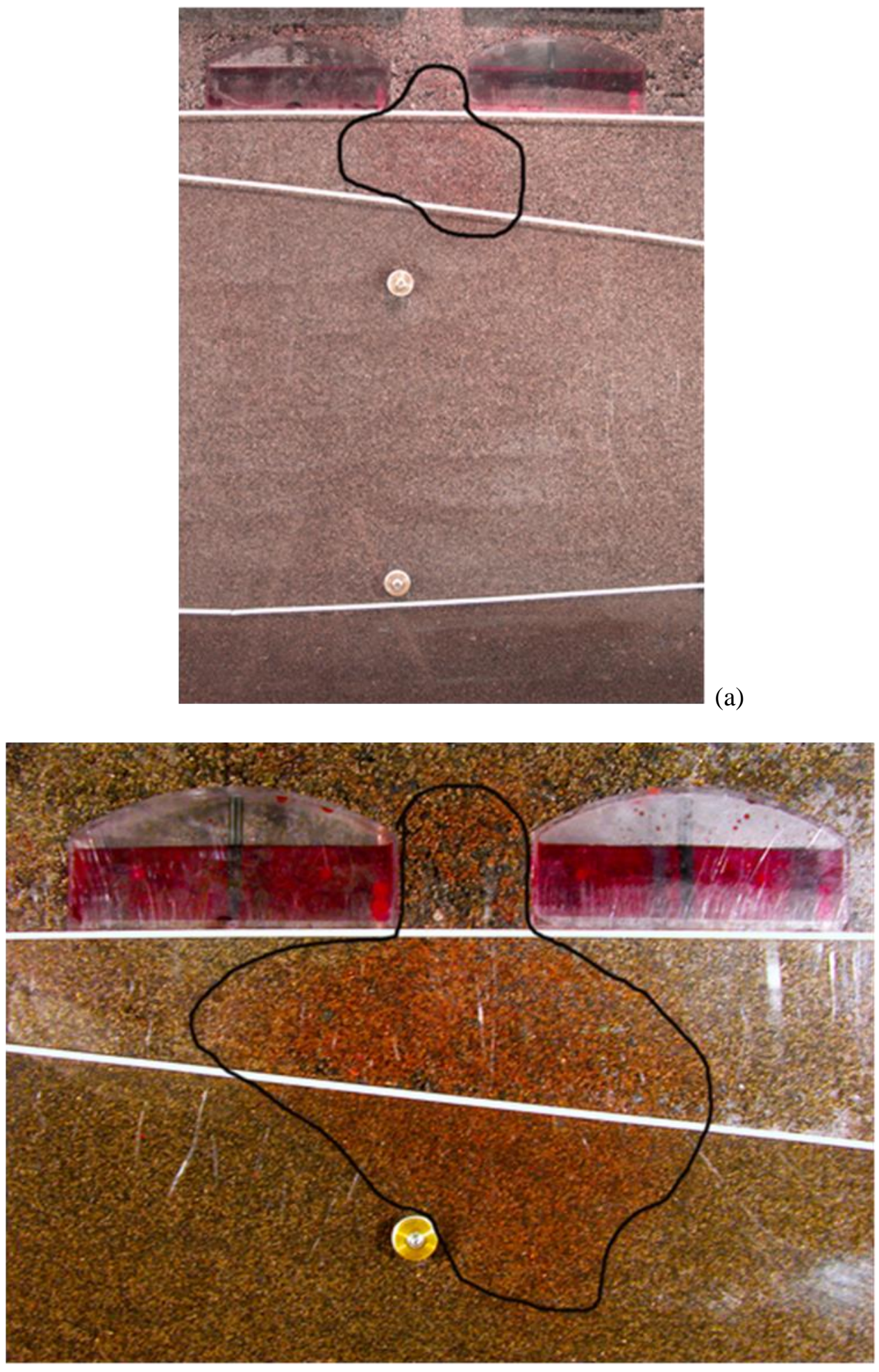

(b)

Figure 3.19. Dye distribution for Exp. S-2 (a) 1, (b) 3, (c) 5, and (d) 7 days after start of injection. The injection rate was $0.02 \mathrm{~mL} / \mathrm{min}$. 

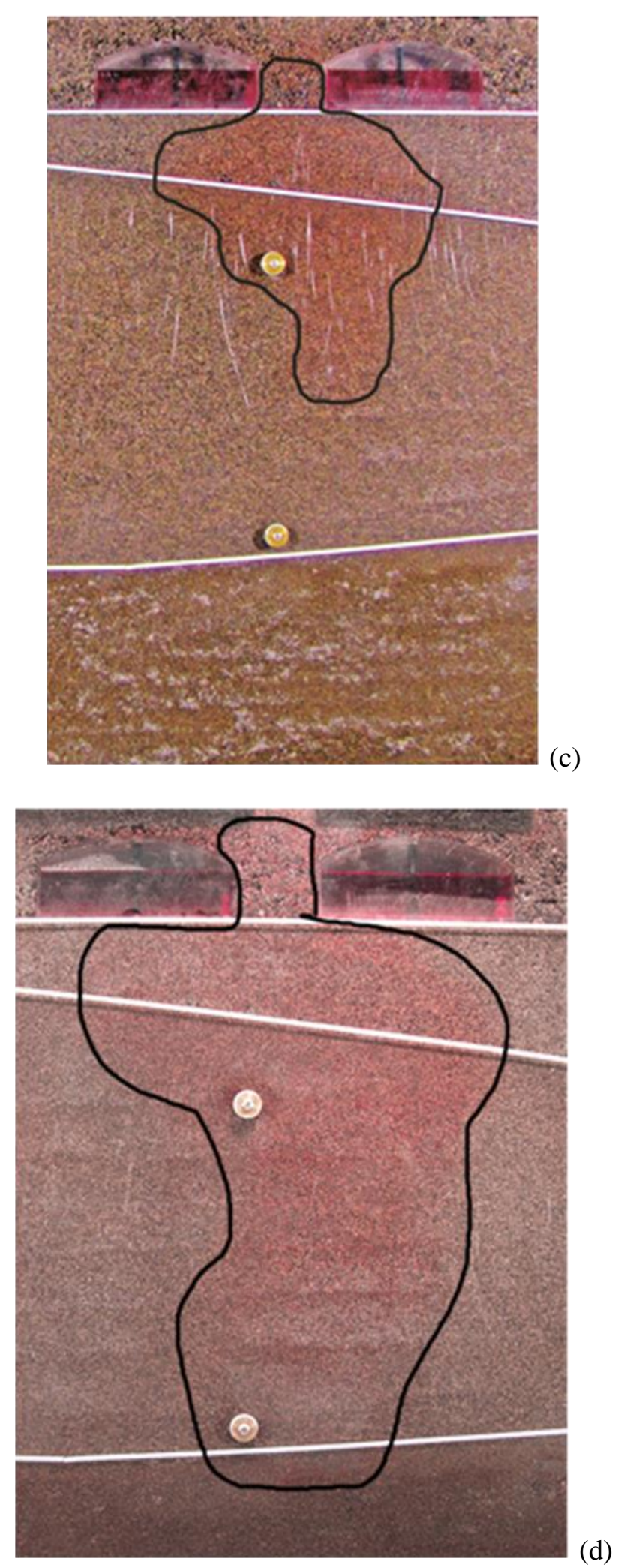

Figure 3.19. (contd) 


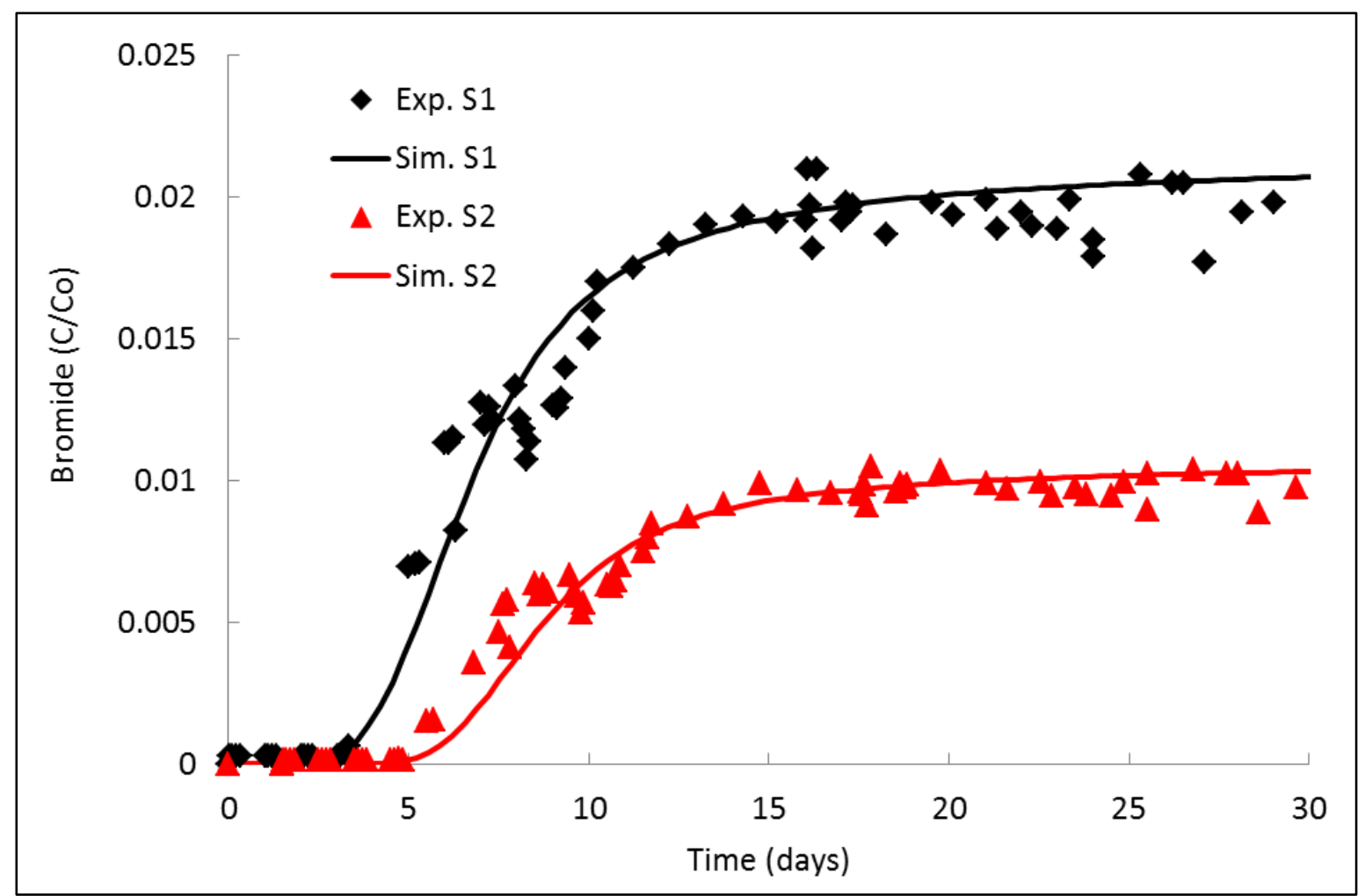

Figure 3.20. Measured and simulated normalized bromide concentrations as a function of time for Exp. S-1 and S-2. 



\subsection{Conclusions}

A series of laboratory experiments and supporting numerical simulations was completed in FY11 to improve the understanding of water flow and contaminant transport in the subsurface between waste tanks and ancillary facilities at Waste Management Area C. Small flow cell experiments were conducted to investigate 1) the occurrence of potential unstable fingering resulting from leaks and 2) the limitations of the STOMP simulator in the simulation of unstable flow. Large flow cell experiments were conducted to investigate the behavior of two types of tank leaks in a simple layered system mimicking the Waste Management Area C: short duration, fast leak rate and long duration, slow leak rate.

\subsection{Small Flow Cell Experiments}

Infiltration experiments were conducted in a small flow cell packed with sand or gravel. Good agreement was observed between the experimental and numerial breakthrough curves for sand. The agreement indicates that for the chosen infiltration rates, in combination with the hydraulic conductivity of the sand, continuum-based models are able to produce reasonable correpondence with experimental observations in terms of breakthrough behavior, although large differences clearly exist between the observed and modeled plume shapes in the unsaturated zone. For the infiltration experiments in gravel, the agreement between experiments and simulations was not nearly as good because the experimentally observed bromide breakthrough started well before the numerically predicted breakthrough for all experiments. The main reason for the larger decrepancies was the limited number of fingers that formed in the more conductive gravel, compared to those that formed in the sand for the same infiltration rate. As a result, the cross-sectional areas in the gravel experiments were smaller, resulting in a more rapid transport of water through the gravel and generally faster arrival times. For gravel, the numerical model overpredicted the arrival times for all rates. The experimental results suggest that unstable fingering behavior is strongly related to the combination of hydraulic conductivity and infiltration rate because flow instabilities are more likely for low leakage conditions in highly permeable sediments. Under these conditions, flow and transport are poorly simulated by the continuum-based model.

The small flow cell experiments show that, at this scale and for the tested uniform sand and gravel, unstable infiltration may create vertically elongated fingers potentially transporting contaminants rapidly through the unsaturated zone to groundwater. However, it is important to recognize that these experiments are part of an initial study examining conditions resulting in unstable downward migration. The experimental results cannot be directly transferred to the field where the likelihood of unstable flow development would be limited by the occurrence of textural interfaces and the presence of non-uniform sediments containing smaller grains. Both aspects increase the impact of capillary action, reducing the formation of downward moving fluid fingers. For the Hanford Site, it will be important to establish a database for the various tanks describing the lower- and upper-bound estimates of leak volumes, durations, and rates. The database should also include sediment hydraulic properties, such as hydraulic conductivity and retention, and information on textural interfaces. Such a database will help identify whether leak infiltration behavior may be simulated appropriately with a continuum-based simulator or whether a dynamic approach is necessary accounting for fingering behavior. 


\subsection{Large Flow Cell Experiments}

Two types of leaks were investigated in the large flow cell. The long duration, slow leak rate experiments resulted in much wider plumes than the short duration, fast leak rate experiments. For both experiment types, good agreement was obtained between experiments and simulations. The satisfactory match between experimental observation and numerical predictions are the result of well-defined boundary and initial conditions, independent determination of the hydraulic properties, the relative simplicity of the experimental system, and the lack of the formation of unstable fingers, as observed in the small flow cell experiments. No fingering was observed because the slow injection rates, in combination with the considerable capillary action in these sediment mixtures, did not allow for any viscous fingers to develop. For these kinds of infiltration experiments in materials of relatively low permeability, the capillary forces tend to dominate the viscous forces and unstable flow patterns do not develop. Similar to the short duration, fast rate experiments, the STOMP simulator was able to predict the breakthrough behavior of the bromide well. The predicted and observed maximum concentrations were relatively close, as were the observed and simulated times that these concentrations occurred.

The large flow cell experiments described in this report were intended to be followed by subsequent experiments with increased subsurface heterogeneity, a larger range of leakage conditions and sediment properties, and the inclusion of (radioactive) contaminants. The work scope has so far not be defined and executed. 


\subsection{References}

Baker RS and D Hillel. 1990. "Laboratory tests of a theory of fingering during infiltration into layered soils.” Soil Science Society of America Journal 54:20-30.

Brown CS, TS Vickerman, RJ Serne, IV Kutnyakov, BN Bjornstad, KN Geiszler, DG Horton, SR Baum, DC Lanigan, KE Parker, RE Clayton, MJ Lindberg, and MM Valenta. 2008. Characterization of Vadose Zone Sediments Below the C Tank Farm: Borehole C4297 and RCRA Borehole 299-E27-22. PNNL15503, Rev. 1, Pacific Northwest National Laboratory, Richland, Washington.

Carroll, K.C., M. Oostrom, M.J. Truex, V.J. Rohay, and M.L. Brusseau. 2012. Assessing Performance and Closure for Soil Vapor Extraction: Integrating Vapor Discharge and Impact to Groundwater Quality. J. Contam. Hydrol. 128:71-82. doi: 10.1016/j.jconhyd.2011.10.003.

Chapwanya M and JM Stockie. 2010. "Numerical simulations of gravity-driven fingering in unsaturated porous media using a nonequilibrium model." Water Resources Research 46, W09534, doi:10.1029/2009WR008583.

Chuoke RL, P van Meurs, and C van der Poel. 1959. "The instability of slow, immiscible, viscous liquidliquid displacements in permeable media." Trans. Am. Inst. Min. Metall. Pet. Eng., 216, 188- 194.

DOE/RL (U.S. Department of Energy, Richland Operations Office). 2011. Feasibility Study for the Plutonium/Organic-Rich Process Condensate/Process Waste Group Operable Unit: Includes the 200PW-1, 200-PW-3, and 200-PW-6 Operable Units. DOE/RL-2007-27, , Richland, Washington.

Freedman VL, MW Williams, CR Cole, MD White, and MP Bergeron. 2002. 2002 Initial Assessments for B-BX-BY Field Investigation Report (FIR): Numerical Simulations. PNNL-13949, Pacific Northwest National Laboratory, Richland, Washington.

Fürst T, R Vodák, M Šír, and M Bíl. 2009. “'On the incompatibility of Richards' equation and finger-like infiltration in unsaturated homogeneous porous media." Water Resources Research, 45, W03408, doi:10.1029/2008WR007062.

Geiger SL and DS Durnford. 2000. "Infiltration in homogeneous sands and a mechanistic model of unstable flow.” Soil Science Society of America Journal 64:460-469.

Glass RJ and MJ Nicholl. 1996. "Physics of gravity fingering of immiscible fluids within porous media: An overview of current understanding and selected complicating factors." Geoderma 70:133-163.

Glass RJ, TS Steenhuis, and J-Y Parlange. 1989. "Mechanism for finger persistence in homogeneous, unsaturated, porous media: Theory and Verification." Soil Science 148:60-70.

Hendrickx JMH, LW Dekker, and OH Boersma. 1993. "Unstable wetting fronts in water repellent field soils." Journal of Environmental Quality 22:109-118.

Jury WA, Z Wang, and A Tuli. 2003. "A conceptual model of unstable flow in unsaturated soil during redistribution." Vadose Zone Journal 2:61-67.

Mualem Y. 1976. "A new model predicting the hydraulic conductivity." Geoderma 65:81-92. 
Oostrom M, JH Dane, and TW Wietsma. 2005. "Removal of carbon tetrachloride from a layered porous medium by means of soil vapor extraction enhanced by desiccation and water table reduction." Vadose Zone Journal 4:1170-1182.

Oostrom M, TW Wietsma, JH Dane, MJ Truex, and AL Ward. 2009. "Desiccation of unsaturated porous media: Intermediate-scale experiments and numerical simulation." Vadose Zone Journal 8:643-650.

Rockhold ML, MJ Fayer, and GW Gee. 1988. Characterization of unsaturated hydraulic conductivity and the Hanford Site. PNNL-6488, Pacific Northwest National Laboratory, Richland, Washington .

Schroth MH, SJ Ahearn, JS Selker, and JD Istok. 1996. "Characterization of miller-similar silica sands for laboratory hydrologic studies.” Soil Science Society of America Journal 60:1331-1339.

van Genuchten MTh. 1980. "A closed-form equation for predicting the hydraulic conductivity of unsaturated soils.” Soil Science Society of America Journal 44:892-898.

Wang Z, A. Tuli, and WA Jury. 2003. "Unstable flow during redistribution in homogenous soil." Vadose Zone Journal 2:52-60.

White MD and M Oostrom. 2006. STOMP Subsurface Transport Over Multiple Phases, Version 4.0, User's Guide. PNNL-15782, Pacific Northwest National Laboratory, Richland, Washington.

White MD, M Oostrom, MD Williams, CR Cole, and MP Bergeron. 2001. FY00 Initial Assessments for $S$-SX Field Investigation Report (FIR): Simulations of Contaminant Migration with Surface Barriers. PNWD-3111, Battelle - Pacific Northwest Division, Richland, Washington.

Wietsma TW, M Oostrom, MA Covert, TW Queen, and MJ Fayer. 2009. “An automated apparatus for constant flux, constant head, and falling head hydraulic conductivity measurements." Soil Science Society of America Journal 73:466-470.

Zhang ZF, SR Waichler, VL Freedman, and MD White. 2004. 2004 Initial Assessments of Closure for the S-SX Tank Farm: Numerical Simulations. PNNL-14604, Pacific Northwest National Laboratory, Richland, Washington. 


\section{Appendix A}

\section{Experimental Plan}





\section{Appendix A}

\section{Experimental Plan}

\section{Experimental Plan FY 2011}

\section{Project Title: PNNL Experimental Support of WMA C PA Working Sessions}

Mart Oostrom and Tom Wietsma

December 6, 2010

\section{Scope}

Experiments will be conducted in a small flow cell $(50 \mathrm{~cm}$ long, $40 \mathrm{~cm}$ high, $5 \mathrm{~cm}$ wide) and in a large flow cell (100 cm long, $80 \mathrm{~cm}$ high, $5 \mathrm{~cm}$ wide) as a part of an initial phase to support an understanding of water flow and contaminant transport in the subsurface between waste tanks and ancillary facilities at Waste Management Area C. A schematic of such a subsurface at the Hanford Site is shown in Figure 1.

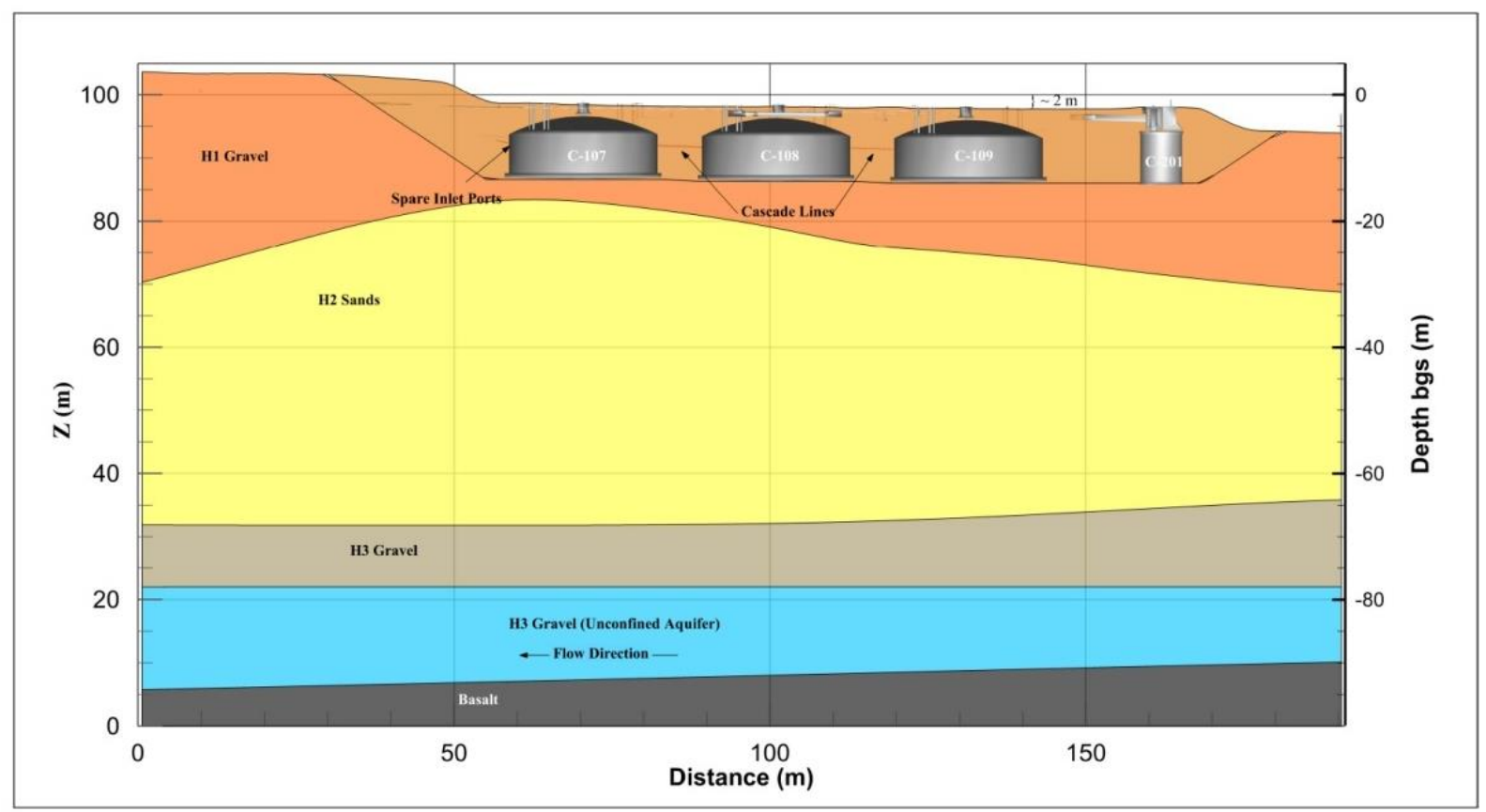

Figure 1. Schematic of a waste tank site at Hanford. The sediments in this relatively simple cross section consist of H1 Gravel, H2 Sand, and H3 Gravel. Groundwater flow is from right to left.

A small flow cell will be used to test the water flow behavior from constant flux leaks in sediments representative of Hanford $\mathrm{H} 2$ sands and $\mathrm{H} 3$ gravels. A schematic of the experimental setup is shown in 
Figure 2. The hydraulic conductivity and retention parameters of both sediments will be independently obtained used techniques described in Wietsma et al. (2009). Based on the determined hydraulic conductivity, water will be injected with $0.01,0.05,0.1,0.25,0.5,0.75$, and 1.0 times the hydraulic conductivity from a small source area. The water will contain a blue dye and a solute (e.g., bromide). The infiltration process will be photographed. A dual-energy gamma radiation system (Oostrom et al. 1998) will be used to determine porosity and water contents during the infiltration experiments. Effluent water samples will be obtained to determine the breakthrough behavior. It is expected that the infiltration will be unstable, leading to "fingers" for low injection rates and that more stable infiltration patterns will develop at the higher rates. The infiltration patterns will have a large effect on contaminant resident time and breakthrough behavior.

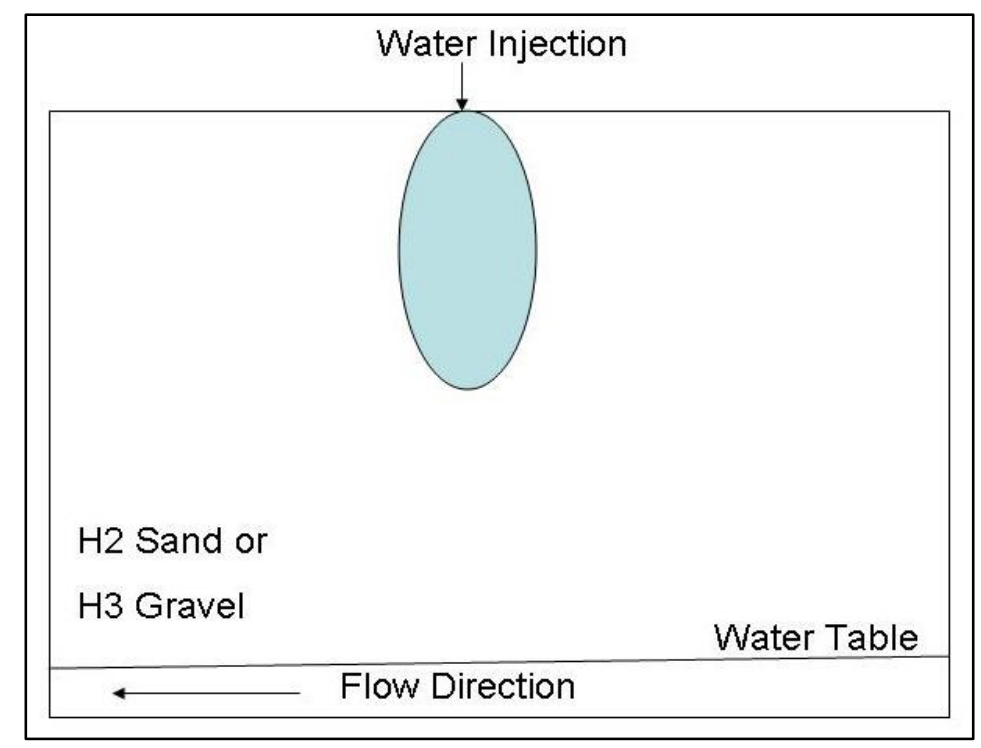

Figure 2. Schematic of small flow cell experiments testing investigating infiltration behavior into an unsaturated sand or gravel as a function of infiltration rate.

The large flow cell experiment will be used to experimentally simulate a chronic leak and a large leak event. A schematic of the packing is presented in Figure 3. The packing is a scaled-down version of the configuration shown in Figure 1. The chronic leak, with an equivalent rate of $0.5 \mathrm{gpm}$, originated from Tank 1 in Figure 2. The large leak event, with an equivalent rate of 100,000 gal/month, is injected through Tank 3 in Figure 3. Both leaks will contain dyes and (different) solutes. The solute concentrations will be obtained from effluent samples. Dual-energy gamma radiation will be used to obtain water saturations. The infiltration process will be documented with photographs.

\section{Deliverable:}

Experimental Results: July 2011

\section{Budget}

$\$ 70 \mathrm{~K}$ total

Spend Plan

December 2010 \$3K

January 2011 \$3K

February $2011 \$ 10 \mathrm{~K}$ 
March $2011 \$ 10 \mathrm{~K}$

April 2011 \$10K

May 2011 \$14K

June $2011 \$ 10 \mathrm{~K}$

July $2011 \$ 10 \mathrm{~K}$

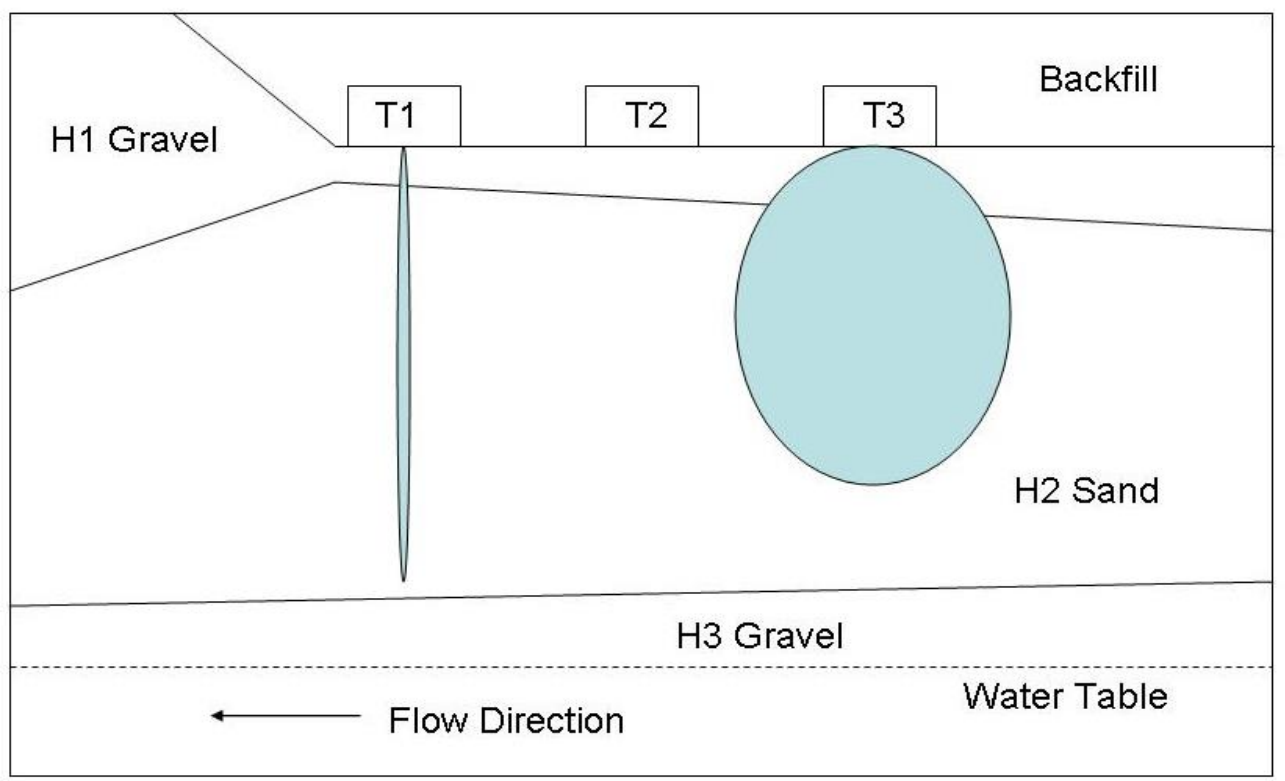

Figure 3. Schematic of large flow cell experiments with a chronic leak from Tank 1 and a large leak event from Tank 3. The spills consist of water with dissolved tracers (dyes and bromide).

\section{References}

Oostrom M, C Hofstee, JH Dane, and RJ Lenhard. 1998. "Single-source gamma radiation for improved calibration and measurements in porous media systems." Soil Science 163:646-656.

Wietsma TW, M Oostrom, MA Covert, TW Queen, and MJ Fayer. 2009. “An automated apparatus for constant flux, constant head, and falling head hydraulic conductivity measurements." Soil Science Society of America Journal 73:466-470. 

PNNL-23586

\section{Distribution}

No. of

Copies

2 DOE Office of River Protection

RD Hildebrand

PDF

CJ Kemp

PDF

3 Washington River Protection Solutions

M. Bergeron

SJ Eberlein

DL Parker

PL Rutland

KM Singleton
No. of

$\underline{\text { Copies }}$
5 Local Distribution

Pacific Northwest National Laboratory MJ Fayer

M Oostrom

MJ Truex

TW Wietsma

PDF

PDF

PDF

Hanford Technical Library
PDF

PDF

Distr.1 


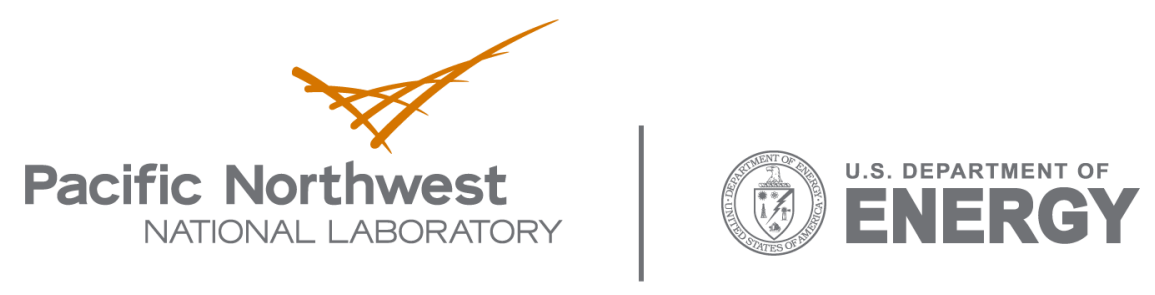

902 Battelle Boulevard

P.O. Box 999

Richland, WA 99352

1-888-375-PNNL (7665)

www.pnl.gov 